\title{
El Paleoceno-Mioceno de Península Mitre: antefosa y depocentro de techo de cuña de la cuenca Austral, Tierra del Fuego, Argentina
}

\author{
Pablo J. Torres Carbonell ${ }^{1}$, Norberto Malumián², Eduardo B. Olivero ${ }^{1}$
}

\author{
${ }^{1}$ Centro Austral de Investigaciones Cientificas (CADIC), CONICET. B. A. Houssay 200, (9410) Ushuaia, Tierra del Fuego, Argentina. \\ polmacleod@hotmail.com; emolivero@ciudad.com.ar \\ 2 SEGEMAR y CONICET. Benjamín Lavaissé 1194, (1107) Buenos Aires, Argentina. \\ n.malumián@yahoo.com
}

\begin{abstract}
RESUMEN. El sistema de cuenca de antepaís Austral-Malvinas adyacente al orógeno Fueguino comprende sedimentitas marinas expuestas en el norte de Península Mitre, incluyendo $550 \mathrm{~m}$ de la antefosa del Paleoceno tardío-Eoceno temprano, y más de $2.900 \mathrm{~m}$ de la subcuenca María Luisa, depocentro de techo de cuña ('wedge-top') del Eoceno medio tardío-?Mioceno. La columna se subdivide en las formaciones La Barca (100 m, Paleoceno superior), Punta Noguera (450 m, Eoceno inferior), Leticia (30 m, Eoceno medio superior), Cerro Colorado ( $935 \mathrm{~m}$, Eoceno medio superior-Eoceno superior), Puesto José (nom. nov., 1.600 m, Oligoceno) y Malengüena (nom. nov., 216 m, ?Mioceno). La microfauna de la Formación Malengüena se distingue por el dominio de Globocassidulina cf. brocha, y por su peculiar preservación, ambas características no reconocidas previamente en la porción argentina de la cuenca Austral. Se verifican discordancias sintectónicas entre el límite Paleoceno-Eoceno y el Eoceno medio, asociadas a una etapa de orogénesis regional: en el Eoceno más alto-Oligoceno basal, relacionada localmente con el anticlinal Campo del Medio; en el Oligoceno 'medio', asociada al retrocorrimiento Malengüena; y en el Mioceno ?inferior, relacionada con estructuras profundas de la faja corrida y plegada.
\end{abstract}

Palabras claves: Paleoceno-Mioceno, Cuenca de antepaís, Techo de cuña, Bioestratigrafia, Discordancias, Tierra del Fuego,

Argentina.

\begin{abstract}
The Paleocene-Miocene of Península Mitre: foredeep and wedge-top of the Austral Basin, Tierra del Fuego, Argentina. The orogenic margin of the Austral-Malvinas foreland basin system is formed by a marine succession exposed at northern Península Mitre, composed of $550 \mathrm{~m}$ of the late Paleocene-early Eocene foredeep, and more than 2,900 m of the late middle Eocene-?Miocene María Luisa wedge-top sub-basin. The succession is subdivided in the following formations: La Barca (100 m, upper Paleocene), Punta Noguera (450 m, lower Eocene), Leticia (30 m, upper middle Eocene), Cerro Colorado ( 935 m, upper middle Eocene-upper Eocene), Puesto José (nom. nov., 1,600 m, Oligocene) and Malengüena (nom. nov., $216 \mathrm{~m}$, ?Miocene). The foraminiferal content of the Malengüena Formation is distinguished by the dominance of Globocassidulina cf. brocha, and by its particular preservation, features not previously recognized in the Argentinean part of the Austral Basin. Syntectonic unconformities are recognized between the Paleocene-Eocene boundary and the middle Eocene, related to regional orogenesis; in the uppermost Eocene-lowermost Oligocene, locally related to the Campo del Medio anticline; in the 'mid' Oligocene, associated with the Malengüena backthrust; and in the ?lower Miocene, related to deep structures of the thrust-fold belt.
\end{abstract}




\section{Introducción}

\subsection{Antecedentes}

El cuadro estratigráfico del Cenozoico del sistema de cuenca de antepaís Austral ha sido elaborado a partir de datos de subsuelo (Criado Roque et al., 1959; Natland et al., 1974; Yrigoyen, 1989; Masiuk et al., 1990a, b; Galeazzi, 1998), y de superficie en la Isla Grande de Tierra del Fuego (De Ferrariis en Fossa Mancini et al., 1938; Furque y Camacho, 1949; entre otros), los cuales han sido correlacionados en la porción argentina de la Isla Grande mediante el estudio de foraminíferos (Olivero y Malumián, 1999; Malumián y Olivero, 2006). Recientemente, a través del análisis sistemático de las sucesiones fueguinas que componen la cuenca de antepaís, expuestas particularmente en los acantilados de la costa Atlántica, se obtuvo una columna bioestratigráfica casi completa desde el Campaniano-Maastrichtiano al Mioceno-Plioceno (Olivero y Malumián, 2008; Malumián y Olivero, 2008; Malumián et al., 2008a; y bibliografía allí citada). Sin embargo, en el área de estudio, entre el cabo Malengüena y la punta Ainol (entre $54^{\circ} 32^{\prime}$ y $54^{\circ} 36^{\prime} \mathrm{S}$ ), la geología es poco conocida y los antecedentes se remontan a Furque y Camacho (1949) y a Olivero y Malumián (1999), que sirvieron de base para la agrupación informal de las rocas por Ghiglione (2003), Ghiglione y Ramos (2005), y Olivero et al. (2007).

El espeso paquete sedimentario marino aflorante en el área de estudio incluye al menos $550 \mathrm{~m}$ del Paleoceno superior-Eoceno inferior (formaciones La Barca y Punta Noguera) y más de $2.900 \mathrm{~m}$ de rocas del Eoceno medio superior-?Mioceno. Estas últimas corresponden a parte de los Estratos de Leticia del Cretácico Superior de Furque y Camacho (1949), al Eoceno-Oligoceno de Ghiglione y Ramos (2005) y a las formaciones Leticia y Cerro Colorado (Eoceno medio superior) de Olivero et al. (2007), mencionadas de manera informal en los citados trabajos. El objetivo de esta contribución es la descripción de la sucesión sedimentaria del Paleoceno superior al ?Mioceno de la costa norte de Península Mitre, la discusión de sus relaciones estratigráficas dentro de la costa Atlántica Fueguina, la descripción de las estructuras tectónicas más notables en el área y la interpretación de la evolución geológica de la porción estudiada del sistema de cuenca de antepaís. La sucesión constituye la columna del Cenozoico más espesa expuesta de manera continua a lo largo de la costa Atlántica Fueguina, y su estudio contribuye al mejor entendimiento de las relaciones entre tectónica y sedimentación en la cuenca de antepaís.

Las sedimentitas del Eoceno medio superior?Mioceno forman parte del relleno de la subcuenca María Luisa, que constituye el depocentro de techo de cuña ('wedge-top', cf. DeCelles y Giles, 1996) del sistema de cuenca de antepaís Austral (y Malvinas occidental), activo a partir del Eoceno medio tardío (Torres Carbonell et al., 2008a). El depocentro de techo de cuña forma parte integral de la cuenca Austral, y se distingue por sucesiones equivalentes a las reconocidas en el resto de la cuenca, depositadas bajo el control de estructuras activas de la faja corrida y plegada. Esta distinción es posible en Tierra del Fuego mediante el reconocimiento y datación de discordancias, secuencias sedimentarias, y estructuras tectónicas relacionadas. La estratigrafía de la subcuenca María Luisa se conoce en considerable detalle solamente en el sector de la estancia epónima, entre 20 y $50 \mathrm{~km}$ al norte del área de estudio (Olivero y Malumián, 1999; Torres Carbonell et al., 2008a; Olivero et al., 2008), por lo tanto este trabajo contribuye a la mejor identificación de las sucesiones involucradas en el depocentro de techo de cuña.

Mediante nuevos datos sedimentológicos, estructurales, y bioestratigráficos basados en foraminíferos, se subdivide el espeso paquete del Eoceno medio superior-?Mioceno en cuatro formaciones identificables o correlacionables con las conocidas en las cuencas Austral y Malvinas en la Isla Grande de Tierra del Fuego: formaciones Leticia y Cerro Colorado (Eoceno medio superior a Eoceno superior; Olivero y Malumián, 1999), Formación Puesto José (nom. nov.), Oligoceno, y Formación Malengüena (nom. nov.) ?Mioceno.

\subsection{Metodología}

Se accede al área de estudio, localizada en terrenos de la Estancia Policarpo, por la ruta provincial 'a' hasta $10-15 \mathrm{~km}$ al norte del cabo Malengüena (Fig. 1C), continuando mediante cuatriciclos, caballos o a pie. Seis campañas que totalizan 28 días fueron realizadas por P.T.C. y E.B.O. aplicadas a la confección de un mapa geológico a escala 1:10.0001:5.000 y de perfiles estratigráficos a escala 1:2.000 y 1:1.000. Los perfiles se levantaron mediante el uso de telémetro láser a lo largo de la costa donde las sucesiones se encuentran mejor expuestas. 
Las mediciones de direcciones de paleocorrientes se tomaron sobre fósiles orientados y estructuras sedimentarias indicativas de corrientes (ondulitas, turboglifos y lineación de partición -"parting lineation'-). Se colectaron 114 muestras con fines micropaleontológicos, con intervalos de muestreo que varían entre $10 \mathrm{~m}$ y $180 \mathrm{~m}$; promediando $35 \mathrm{~m}$ para la Formación Cerro Colorado (33 muestras), $60 \mathrm{~m}$ para la Formación Puesto José (63 muestras) y 20 m para la Formación Malengüena (18 muestras). En el Paleoceno superior-Eoceno inferior se tomaron entre 2 y 4 muestras de cada formación para posibilitar la correlación con sus perfiles tipo. La bioestratigrafía se basó en los foraminíferos y sus determinaciones fueron expeditivas en la medida en que se colectaron las muestras, preparadas de acuerdo con métodos convencionales. La cantidad de muestra analizada superó en algunos casos los $400 \mathrm{~g}$, dependiendo de la verificación de las primeras y últimas apariciones de los foraminíferos planctónicos guías. Adicionalmente se dispuso de una treintena de muestras de las márgenes del río Malengüena de las formaciones La Barca y Punta Noguera, colectadas por E.B.O. y estudiadas por N.M. en el año 2001. Los microfósiles y las muestras correspondientes se archivaron en el Laboratorio de Micropaleontología del SEGEMAR.

\section{Sistema de Cuenca de Antepaís Austral- Malvinas}

Las cuencas Austral y Malvinas forman un sistema de cuenca de antepaís desarrollado en el lado cratónico de los Andes Patagónicos AustralesFueguinos (Biddle et al., 1986; Dott et al., 1982; Wilson, 1991; Galeazzi, 1998; Fig. 1). La evolución de este sistema está asociada al crecimiento del orógeno Fueguino, formado luego del cierre de una cuenca de retroarco en el margen sudoccidental de Gondwana (Dalziel et al., 1974, 1987) durante el Cretácico Tardío (Dott et al., 1982; Olivero y Martinioni, 1996). La formación del sistema de cuenca de antepaís entre el Campaniano y el Mioceno (Olivero et al., 2003; Malumián y Olivero, 2006) responde a la flexura litosférica producida por la carga tectónica del orógeno en crecimiento (cf. Allen y Allen, 1990). Los dos depocentros principales del sistema, las cuencas Austral y Malvinas, se encuentran parcialmente desconectados por un promontorio del basamento tectónico llamado arco Río Chico (Fig. 1A; Biddle et al., 1986; Robbiano et al., 1996;
Galeazzi, 1998). En general, las descripciones geológicas del Cenozoico de la Isla Grande de Tierra de Fuego se han referido a la cuenca Austral (e.g., Masiuk et al., 1990a, b), aunque más recientemente se han comparado los patrones estratigráfícos de la Isla y de la cuenca Malvinas occidental, dado que salvo leves diferencias cronológicas ambos depocentros del sistema han evolucionado de manera similar (cf. Biddle et al., 1986; Galeazzi, 1998; Olivero et al., 2002).

En la Isla Grande de Tierra del Fuego, las rocas de las cuencas Austral y Malvinas se encuentran en gran parte involucradas en la faja corrida y plegada Fueguina. Los cuadros estratigráficos existentes muestran una progresión de los depocentros sedimentarios hacia el antepaís entre el Cretácico Tardío y el Mioceno, con algunas secuencias claramente restringidas al sector adyacente al orógeno. Este patrón es típico de sistemas de cuenca de antepaís asociados a fajas corridas y plegadas (Olivero y Malumián, 2002; Ghiglione, 2003; Ghiglione y Ramos, 2005; Torres Carbonell et al., 2008a).

Se han reconocido al menos dos paquetes sedimentarios mayores del Cenozoico en el ámbito oriental de la faja corrida y plegada Fueguina, separados por una discordancia regional (llamada P3, cf. Galeazzi, 1998). El primer paquete involucra una sucesión del Paleoceno superior al Eoceno inferior, que se acumuló en la porción de la antefosa de la cuenca adyacente al frente de deformación, localizado durante ese período en Península Mitre (Olivero y Malumián, 2008; Torres Carbonell et al., 2008a; Fig. 1). Diferentes interpretaciones asignan parte de este paquete (Eoceno inferior) a depósitos de 'rift' (Ghiglione et al., 2008). El segundo paquete comprende estratos del Eoceno medio superior al Mioceno inferior, depositados en la cuenca luego de una importante etapa de levantamiento orogénico entre el límite Paleoceno-Eoceno y el Eoceno medio temprano (Torres Carbonell et al., 2008a, b). El frente de deformación formado luego de esa etapa de orogénesis dividió el sistema de cuenca de antepaís en dos dominios distintos (Fig. 1C): la antefosa de la cuenca hacia el norte de dicho frente, y el depocentro de techo de cuña, llamado subcuenca María Luisa, hacia el sur sobre las estructuras de la faja corrida y plegada. El paquete del Eoceno medio superiorMioceno inferior se acumuló simultáneamente en ambos dominios durante un período caracterizado por subsidencia en la cuenca, erosión de los Andes Fueguinos, y deformación interna de la cuña oro- 

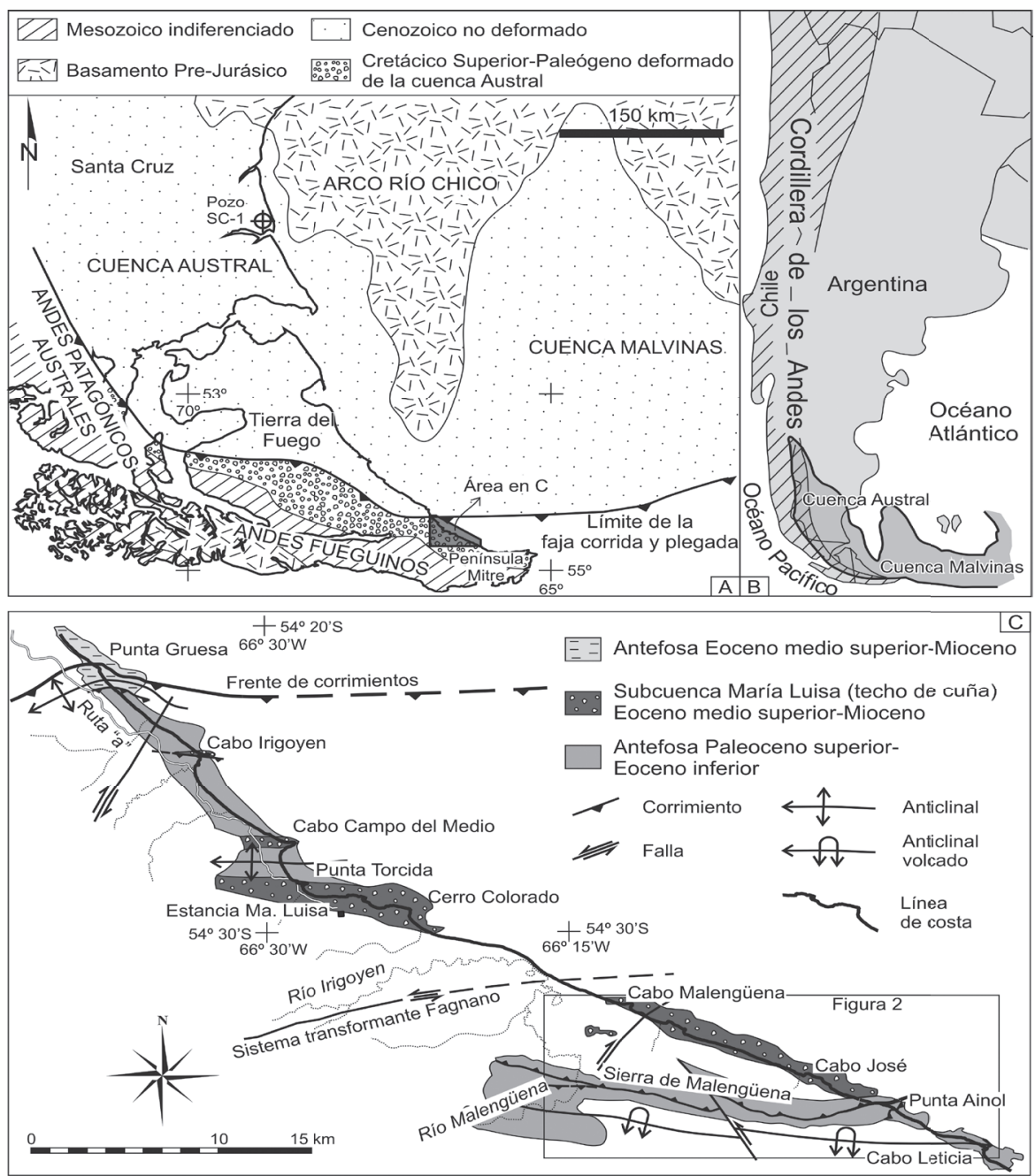

FIG. 1. Posición relativa y geología regional del área de estudio en A. Tierra del Fuego y B. América del Sur. Las líneas oblicuas en B indican posición de la Cordillera de los Andes. C. Mapa de distribución de los paquetes sedimentarios de la antefosa paleocena superior-eocena inferior, y la subcuenca de techo de cuña y antefosa del Eoceno medio superior-?Mioceno en la costa Atlántica de Tierra del Fuego.

génica. El relleno sedimentario y la evolución de la subcuenca María Luisa sólo se han estudiado en el sector cercano a la estancia epónima, que representa el extremo norte de este depocentro (Torres Carbonell et al., 2008a).

En la costa norte de Península Mitre aflora la parte superior de la antefosa del Paleoceno tardíoEoceno temprano y el paquete del Eoceno medio tardío-?Mioceno correspondiente al relleno de la subcuenca María Luisa en ambientes próximos al orógeno Andino (Fig. 1C). Mediante el análisis de la sucesión eocena media superior-?miocena se interpreta la evolución sedimentológica y estructu- ral del depocentro de techo de cuña del sistema de antepaís, en relación con la actividad tectónica de la faja corrida y plegada Fueguina.

\section{Estratigrafía, paleontología y sedimentología}

\subsection{Antefosa del Paleoceno tardío-Eoceno temprano}

Las sedimentitas del Paleoceno superior-Eoceno inferior aflorantes en el extremo sur del área estudiada (Fig. 2) fueron asignadas al Cretácico Superior por Furque y Camacho (1949), al Paleó- 


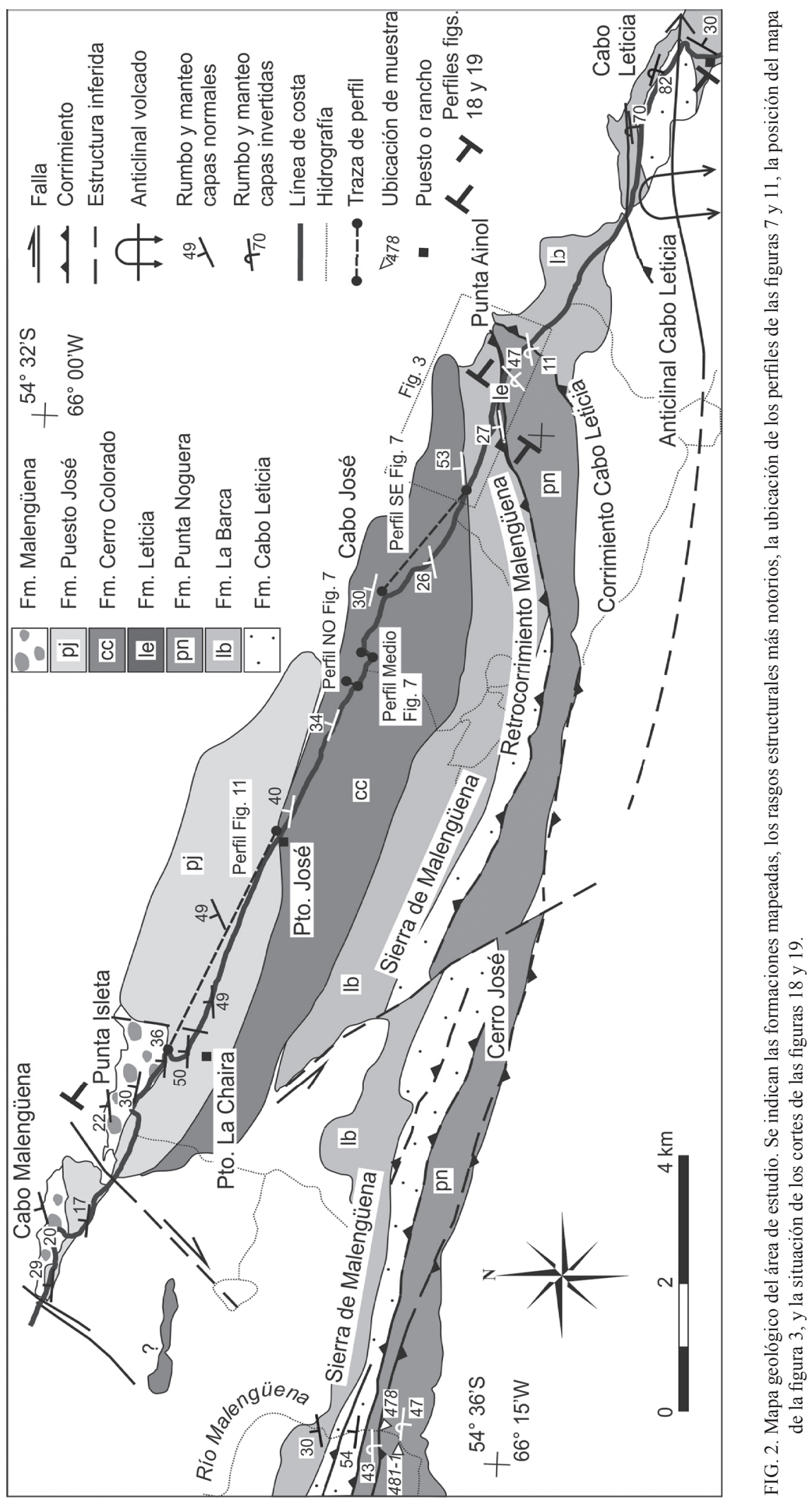


geno (en parte Paleoceno superior) por Ghiglione y Ramos (2005) y al Eoceno medio superior-Eoceno superior por Olivero et al. (2007). Sobre la base de su litología y foraminíferos, estos estratos son identificados aquí con las formaciones La Barca y Punta Noguera del Grupo Río Claro, descrito por Olivero et al. (2002) en Península Mitre, y consecuentemente reasignados al Paleoceno superior y Eoceno inferior, respectivamente.

\subsubsection{Formación La Barca. Paleoceno superior}

La Formación La Barca (Olivero et al., 2002) aflora en el extremo sur del área de estudio, al norte y al sur de la punta Ainol (Figs. 2 y 3 ). Al sur de la punta Ainol el afloramiento se conecta con el de la playa de La Barca, localidad tipo donde se midieron $220 \mathrm{~m}$ de espesor. La Formación La Barca ha sido subdividida en dos miembros (LB1 y LB2) de los cuales el superior-LB2-, de un mínimo de $100 \mathrm{~m}$ de espesor (Olivero et al., 2002), es el reconocido en el área de estudio. La asignación de las fangolitas del norte de la punta Ainol a la Formación La Barca se debe a las similitudes litológicas con el perfil tipo y a su edad paleocena.

El perfil, de base cubierta, comprende fangolita negra a gris oscura, maciza, con niveles de concreciones elipsoidales que alcanzan los 2,5 $\mathrm{m}$ en su eje mayor. El contacto del techo de esta Formación no se encuentra expuesto, por lo que se desconoce su relación estratigráfica con la más joven e inmediata Formación Punta Noguera. Al sur de la punta Ainol las fangolitas están montadas sobre las areniscas de la Formación Punta Noguera mediante un corrimiento de traza irregular de muy bajo manteo y vergencia norte (Fig. 4A, corrimiento Cabo Leticia).

En el sector norte de la punta Ainol, las rocas deformadas de la Formación La Barca constituyen un par anticlinal-sinclinal con ejes de rumbo aproximado $\mathrm{N} 100^{\circ}$ e inclinación oeste. Las concreciones en este sector son muy abundantes y la macrofauna hallada se limita a un ejemplar de pectínido. Las fangolitas están corridas sobre la Formación Leticia mediante una falla inversa de vergencia sur en el extremo meridional del afloramiento (corrimiento M2), mientras que hacia el norte la Formación La Barca es cubierta discordantemente por la Formación Leticia (Figs. 3 y 4).

Microfósiles. En dos muestras se hallaron sólo foraminíferos bentónicos y espículas silíceas de esponjas. En una, del norte de la punta Ainol (PT Nor), sólo foraminíferos aglutinados: Spiroplectammina
spectabilis(Grzybowski)dominante, Gaudryinopsis sp. y Haplophragmoides sp.; en la otra del sur (PT Sur), escasos foraminíferos pero muy bien conservados: S. spectabilis dominante, Alabamina creta (Finlay), Anomalinoides sp., Charltonina acutimarginata (Finlay), Gyroidinoides sp., Lenticulina sp., Nodosaria longiscata (d'Orbigny), Stensioeina beccariiformis (White), Stilostomella sp. Como accesorios, se reconocen radiolarios esféricos y abundantes espículas de esponjas silíceas. El conjunto de foraminíferos calcáreos es notoriamente diferente, considerando que se trata de microfaunas de similar edad, respecto a la asociación de Bulimina karpatica del miembro inferior (LB1) de la Formación (Malumián y Caramés, 2002).

$\boldsymbol{E} \boldsymbol{d a d}$. Es la primera vez que se hallan foraminíferos calcáreos en el miembro superior de la Formación La Barca, los cuales verifican la edad asignada previamente a toda la Formación pero sólo basada en foraminíferos del miembro inferior. Alabamina creta, Ch. acutimarginata, y S. beccariiformis son especies que se reconocen desde el Maastrichtiano hasta el Paleoceno de Nueva Zelanda (cf. Hornibrook et al., 1989), en particular la primera en Tierra del Fuego se distribuye hasta la Formación Punta Noguera, y la última es una especie cosmopolita que se extingue hacia el límite Paleoceno-Eoceno. En conjunto conforman una asociación típica del Paleoceno.

\subsubsection{Formación Punta Noguera. Ypresiano inferior. 55,80-53,39 $\mathrm{Ma}$}

Las areniscas finas con niveles intercalados de heterolitas expuestas en la punta Ainol son asignadas a la Formación Punta Noguera por su litología, su posición estratigráfica superior respecto de la Formación La Barca (inferida por su contacto mediante un corrimiento, Figs. 3 y 4A) y por el elevado contenido de material volcánico, principalmente cristales límpidos de plagioclasa y fragmentos de volcanita cloritizada, característico de la Formación Punta Noguera (Olivero et al., 2002; Olivero, 2002). El espesor mínimo estimado para la Formación es de $450 \mathrm{~m}$, con base y techo cubiertos. Se desconoce su contacto estratigráfico normal con la Formación La Barca.

Los niveles de arenisca fina constituyen paquetes grano-estrato decrecientes de 2 a $4 \mathrm{~m}$ de espesor, compuestos de bancos tabulares de base erosiva, de entre 0,4 y $1,5 \mathrm{~m}$, con bolsones de grava, gradación 


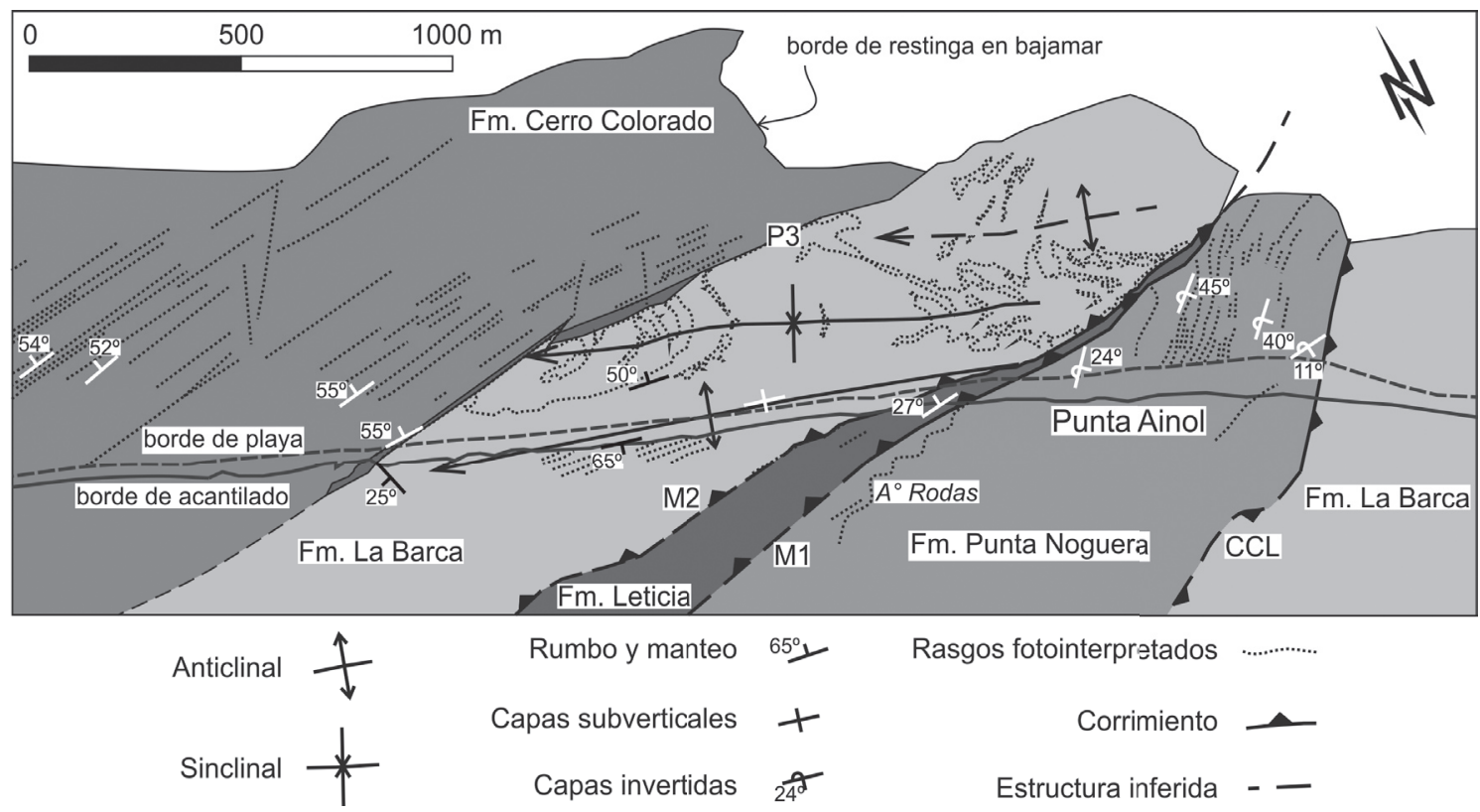

FIG. 3. Mapa geológico del sector de la punta Ainol. Se indican el corrimiento cabo Leticia (CCL), las ramificaciones del retrocorrimiento Malengüena (M1 y M2) y la discordancia P3.

normal a arenisca fina maciza, laminación entrecruzada, laminación paralela, ondulitas de corriente y ondulitas escalonadas, estructuras de deformación por carga y escape de agua, abundantes restos vegetales e intraclastos de arcilla (Fig. 5). Los bancos individuales tienen sucesivas repeticiones de facies con pasajes gradacionales, ocasionalmente con múltiples superficies de corte y relleno interestratales, pero sin planos definidos que representen pausa en la sedimentación. Los paquetes heterolíticos tienen de 2 a $3 \mathrm{~m}$ de espesor, y se componen de una alternancia de capitas de fangolita y arenisca muy fina con abundantes fragmentos de plantas y moderada a intensa bioturbación (Fig. 5A, F), e intercalaciones menores de bancos de arenisca de menos de $0,3 \mathrm{~m}$ de espesor.

Las capas de la Formación Punta Noguera en la punta Ainol están invertidas (Figs. 3 y 5A, C, D) con una orientación promedio $\mathrm{N} 52^{\circ}$ y manteo entre $40^{\circ}$ y $10^{\circ} \mathrm{SE}$, aunque con variaciones locales en el rumbo debido a la intensa deformación. Las capas aumentan el grado de inversión hacia el sureste, cerca del contacto tectónico con la Formación La Barca, donde mantean $\sim 10^{\circ} \mathrm{SE}$. Se reconocen algunas fallas verticales de rumbo NO, con desplazamientos horizontales máximos de $\sim 20 \mathrm{~m}$.
Hacia el noroeste, la Formación Punta Noguera limita con la Formación Leticia mediante un corrimiento de vergencia sur, muy bien expuesto en la cascada que forma la desembocadura del arroyo Rodas (Figs. 3 y 4C, corrimiento M1). Esta falla dispone al Eoceno medio superior sobre las areniscas del Eoceno inferior, resultando en una aparente incoherencia estructural producto de la interacción entre tectónica y sedimentación (Capítulo 5).

Microfósiles. De un total de cuatro muestras regularmente espaciadas colectadas en la punta Ainol se hallaron muy escasos foraminíferos sólo en dos de ellas, con S. spectabilis y radiolarios esféricos, que sugieren un ambiente desfavorable para la vida de los foraminíferos.

Edad. En las muestras 478 a 481-1 del río Malengüena (Fig. 2), se hallaron muy abundantes radiolarios indeterminables, y particularmente la 479-2 contiene Rzehakina minima (Cushman y Renz) junto con abundante $S$. spectabilis. Se conoce un solo caso a nivel mundial, en que $R$. minima llega a la zona P6 (cf. Caramés y Malumián, 2006), cuyo techo está en 52,30 Ma según la calibración de Berggren et al. (1995). Recientemente se ha reconocido Chiloguembelina wilcoxensis (Cushman y Ponton) en la sección tipo de la formación (comunicación 

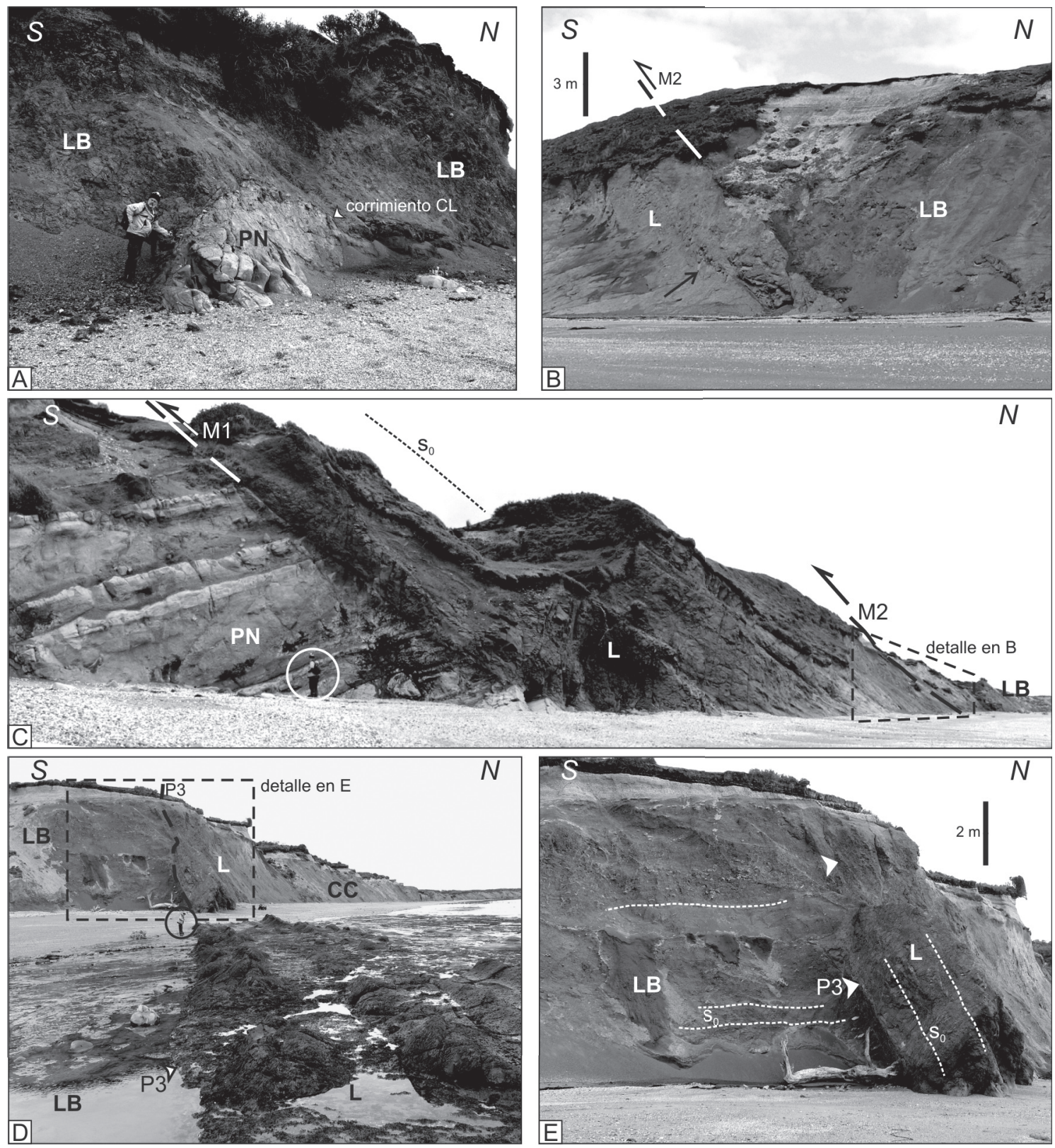

FIG. 4. Detalle de las estructuras expuestas en el sector de la punta Ainol, que afectan a las formaciones La Barca (LB), punta Noguera $(\mathbf{P N})$ y Leticia $(\mathbf{L})$. A. Detalle del corrimiento cabo Leticia $(\mathbf{C L})$. Nótese el bajo manteo y la geometría irregular del plano de falla; B. Detalle del corrimiento M2, la flecha indica el techo; C. Vista panorámica de los corrimientos M1 y M2 en el acantilado de la punta Ainol. $\mathbf{S}_{\mathbf{0}}$ : Estratificación; D y E. Detalle del contacto discordante entre las formaciones La Barca y Leticia (discordancia P3). Nótese la manifiesta angularidad de la discordancia. En D se muestra el contacto difuso entre las formaciones Leticia y Cerro Colorado $(\mathbf{C C})$.

personal de C. Náñez y G. Jannou, agosto de 2008), cuya extinción está estimada en 53,39 Ma. La edad eocena se asigna por los típicos géneros pospaleocenos conocidos para la localidad tipo de la Formación
(Olivero et al., 2002). Los radiolarios asignados al Paleoceno superior por Jannou (2007), serían retrabajados e indicarían una relación discordante con la Formación La Barca. 

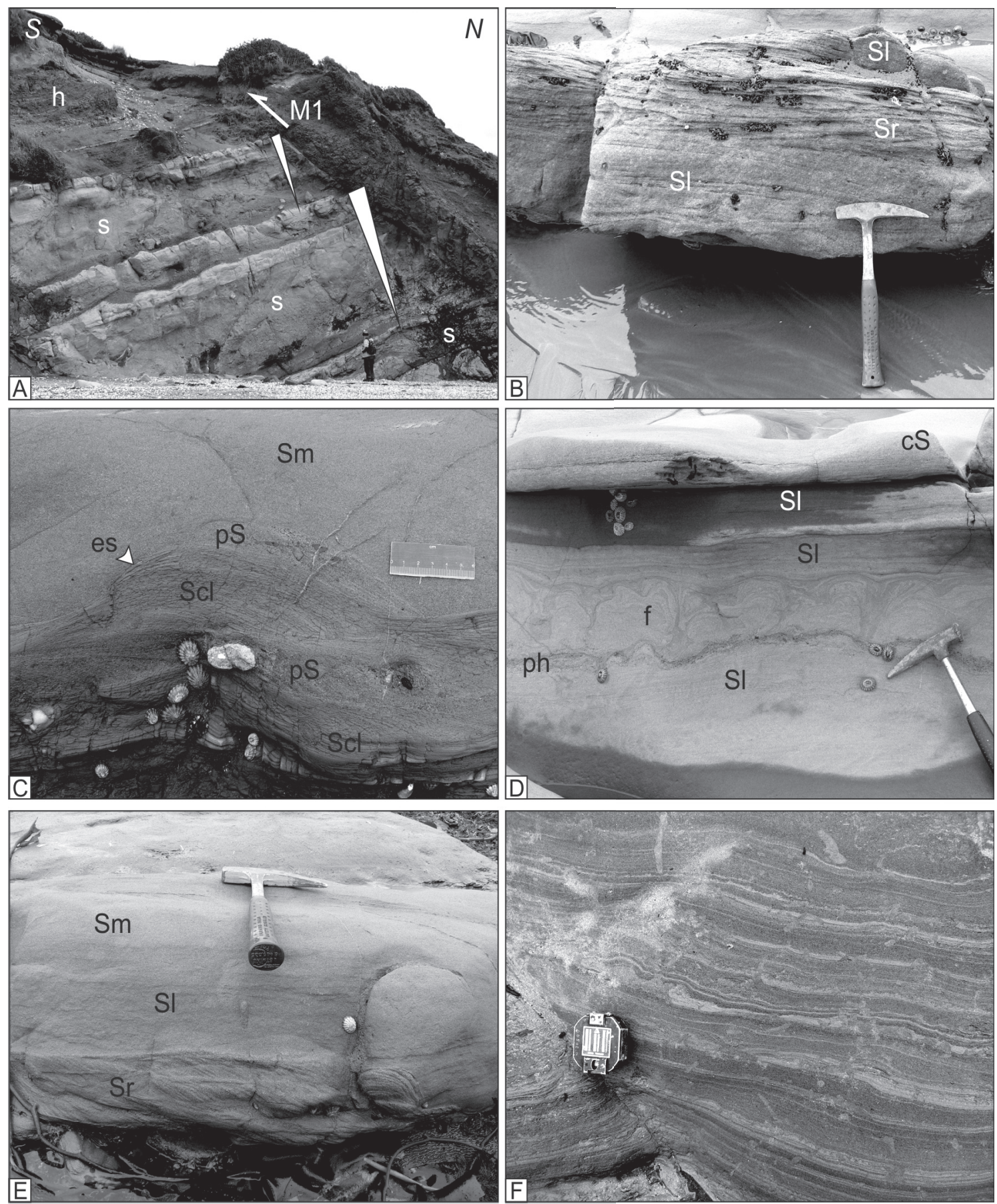

FIG. 5. Detalle de las facies de la Formación Punta Noguera. En todos los casos el techo de las capas es hacia abajo. A. Paquetes invertidos de arenisca grano-estrato decrecientes (s) sobre un paquete heterolítico (h), bajo el corrimiento M1. Nótese las bases erosivas de capas de arenisca; B. Pasaje gradacional entre arenisca con laminación paralela (SI) y ondulitas de corriente (Sr); C. Arenisca maciza (Sm) cubierta mediante una superficie erosiva (es) por alternancias de conglomerado fino (pS) y arenisca con laminación entrecruzada (Scl); D. Arenisca gruesa (cS) cubierta por arenisca con laminación paralela, deformada por carga (f: 'flames'), y con nivel de fitodetritos (ph); E. Pasaje gradacional de arenisca maciza a arenisca con laminación paralela y con ondulitas de corriente al techo; F. Detalle de un paquete heterolítico con intercalaciones de arenisca muy fina y pelita, bioturbadas. Las manchas claras ovaladas en las fotografías son gastrópodos actuales. 


\subsubsection{Paleoambientes del Paleoceno superior- Eoceno inferior}

Las pelitas oscuras del miembro LB2 de la Formación La Barca han sido interpretadas como una sucesión turbidítica de ambientes restringidos y de aguas profundas, acumulados en coincidencia con períodos de volcanismo activo en la región de aporte. Las asociaciones de foraminíferos aglutinados sustentan condiciones de turbidez de fondo con elevado contenido orgánico, dominadas por morfotipos infaunales y de baja diversidad, que junto a la excelente preservación de los foraminíferos calcáreos por niveles indica marcadas condiciones de disoxia. El miembro LB2 probablemente corresponda a las porciones distales del sistema turbidítico de la Formación La Barca. La sucesión grano-estrato decreciente formada por ambos miembros refleja un carácter retrogradante (Olivero et al., 2002).

La Formación Punta Noguera corresponde a los niveles superiores de la antefosa paleocena tardía-eocena temprana de la cuenca. Sus facies y el importante contenido de restos de plantas sugieren depositación por flujos gravitatorios hiperpícnicos. Esta interpretación es coherente con ambientes de cuencas con control tectónico y con altas tasas de aporte clástico provenientes del orógeno adyacente (cf. Mutti et al., 1999, 2003), y es característica en depocentros más jóvenes de la cuenca Austral (Ponce et al., 2008).

Los depósitos de areniscas de la Formación Punta Noguera, con facies muy distintas de las fangolitas del paquete LB2, indican un incremento en la tasa de aporte clástico en relación con el paquete de fangolita-arenisca de la Formación La Barca. La pobre preservación o ausencia de las conchillas de foraminíferos calcáreos puede deberse a una reducción de la salinidad producto del aporte de agua dulce asociada a flujos hiperpícnicos. Este cambio en las condiciones ambientales reflejado en la sedimentación de la cuenca y marcadamente en los foraminíferos con la brusca desaparición de ambientes deficitarios en oxígeno, sugiere una relación discordante con la Formación La Barca, y se interpreta como una respuesta al inicio de la etapa orogénica regional del Paleoceno más tardío al Eoceno medio en los Andes Fueguinos (Kohn et al., 1995). Esta etapa tectónica resultó en la propagación del despegue basal de la faja corrida y plegada hacia el antepaís y en el desarrollo de la dis- cordancia mayor entre el Paleoceno-Eoceno inferior y sedimentitas más jóvenes de las cuencas Austral y Malvinas (Torres Carbonell et al., 2008a, b).

Es notoria la aparente ausencia de foraminíferos planctónicos en el Paleoceno superior y Eoceno inferior, donde se ha preservado el carbonato, salvo en un nivel de la Formación Punta Noguera que contiene especies de Chiloguembelina, género planctónico de pequeño porte y carácter marginal. Esta ausencia o reconocimiento solo de conchillas de planctónicos de pequeño porte se explicaría por condiciones paleogeográficas de un mar marginal con escasa conexión con el mar abierto.

\subsection{Subcuenca María Luisa. Depocentro de techo de cuña del Eoceno medio tardío- ?Mioceno}

\subsubsection{Formación Leticia. Lutetiano superior- Bartoniano inferior. 43,70-39 Ma}

La Formación Leticia fue redefinida por Olivero y Malumián (1999) como parte de los Estratos de Leticia de Furque y Camacho (1949). En la sección tipo, en el sector del cabo Campo del Medio y la punta Torcida ( $\sim 30 \mathrm{~km}$ al NO del área de estudio), sus depósitos alcanzan más de $500 \mathrm{~m}$ de espesor dominado por arenisca. La edad de la formación, determinada mediante foraminíferos y nanoplancton calcáreo, se situó entre las Zonas P12 temprana y P14 media (Lutetiano tardío-Bartoniano medio). Si se actualiza su calibración mediante la zonación propuesta por Huber y Quillévéré (2005) su edad se sitúa entre 43,70 Ma por la aparición de Globigerinatheka index y $39 \mathrm{Ma}$, por la desaparición de Acarinina primitiva. Junto con la Formación Cerro Colorado (ver 3.2.2), la Formación Leticia forma parte del Grupo La Despedida (Olivero y Malumián, 1999).

La Formación Leticia se reconoce en el sector norte de la punta Ainol, asociada a un par de sucesivos corrimientos de vergencia sur que la disponen en dos afloramientos aislados uno de otro (Fig. 3). El afloramiento sur, adyacente a la punta Ainol, está constituido por $c a .29 \mathrm{~m}$ de arenisca mediana verde grisácea, con abundantes clastos de pumicita y bioturbación pervasiva que oblitera la fábrica sedimentaria original. Los $13 \mathrm{~m}$ basales contienen gran cantidad de pelmas de crinoideos isocrínidos, algunos en posición de vida y muchos orientados por corrientes; la parte media se compone de $c a .15 \mathrm{~m}$ 
donde no se reconocen fósiles y el metro superior de la sucesión contiene ejemplares de bivalvos del género Panopea, la mayoría de ellos en posición de vida, y fragmentos de corales y espinas de equinoideos (Fig. 6). Panopea sp. fue mencionada para este sitio por Furque y Camacho (1949).

La Formación Leticia en el afloramiento sur está montada sobre las capas invertidas de la Formación Punta Noguera mediante una falla de vergencia sur bien expuesta en el acantilado y la restinga (Fig. 4C, corrimiento M1). El rumbo de las capas de la Formación Leticia es $\mathrm{N} 85^{\circ}$ y mantean $27^{\circ} \mathrm{N}$, al igual que el corrimiento. En el plano del corrimiento se identifica una cataclasita que varía dentro de las decenas de centímetros de espesor, y tiene continuidad a lo largo de la falla. El límite hacia el norte del afloramiento de la Formación Leticia corresponde a un corrimiento de vergencia sur, que dispone las fangolitas de la Formación La Barca sobre la Formación Leticia (Fig. 4B, corrimiento M2).

En el afloramiento norte, la Formación Leticia comprende un banco de unos 5 a $6 \mathrm{~m}$ de espesor de arenisca fina conglomerádica-brechosa, verde grisácea, con bioturbación pervasiva y abundantes fragmentos de pumicita, que alcanzan un tamaño de arena gruesa-grava fina. Las areniscas contienen bivalvos en posición de vida (Panopea sp.) y restos de corales y de nautiloideos. El rumbo de las capas es $\mathrm{N} 87^{\circ}$, con manteo entre $50^{\circ}$ y $55^{\circ} \mathrm{N}$. El contacto con la Formación La Barca es una discordancia angular (discordancia P3, Fig. 4D, E); mientras que con la suprayacente Formación Cerro Colorado, por el contrario, está poco definido y parcialmente cubierto (Fig. 4D). Se infiere una discordancia, sin embargo, por el brusco cambio de facies y asociaciones de foraminíferos en la base de la Formación Cerro Colorado, y por ser manifiesta en el área tipo de estas formaciones. Sobre la base del contenido fósil y las litofacies se correlaciona el espesor de arenisca del afloramiento norte con la sección superior del afloramiento sur.

Paleoambiente. La abundancia de Panopea sp. en posición de vida, y de fósiles escasamente desplazados, sugiere un ambiente somero en parte por debajo de la acción de olas, aunque la obliteración de las estructuras sedimentarias debida a la intensa bioturbación no permite mayores interpretaciones. Las areniscas de ambientes someros de la Formación Leticia tienen la particularidad de contener pelmas de crinoideos isocrínidos en posición de vida (cf. Malumián y Olivero, 2005), lo cual se ve- rifica en la punta Ainol. El dominio composicional de material volcanoclástico relativamente fresco se atribuye a una actividad volcánica coetánea con la sedimentación, y los fragmentos pumíceos más alterados son producto de la erosión de rocas paleocenas-eocenas tempranas de composición volcanoclástica, tal como se constató en la misma formación en su sección tipo (cf. Olivero y Malumián, 1999; Torres Carbonell et al., 2008a). Esto último se sustenta en la discordancia angular por debajo de la formación, correlativa con la discordancia regional reconocida en las cuencas Austral y Malvinas por arriba del Paleoceno-Eoceno inferior (discordancia P3, Malumián et al., 1971; Biddle et al., 1986; Galeazzi, 1998). Se interpreta que la Formación Leticia corresponde en el área de estudio a depósitos transgresivos someros del relleno inicial de la subcuenca María Luisa, en un ambiente próximo al frente orogénico, durante la etapa de subsidencia posterior al tectonismo del Eoceno temprano-medio (cf. Torres Carbonell et al., 2008b).

\subsubsection{Formación Cerro Colorado. Bartoniano superior-Priaboniano. 39-34,30 Ma}

La parte superior de los Estratos de Leticia de Furque y Camacho (1949) fue definida como Formación Cerro Colorado por Olivero y Malumián (1999), con una sección tipo de $855 \mathrm{~m}$ subdividida informalmente en cuatro miembros (CCa-CCd) en las cercanías del cerro epónimo, a unos $25 \mathrm{~km}$ al NO del área de estudio. Su edad se determinó mediante foraminíferos planctónicos entre las Zonas P14 media y P16 tardía, correspondientes al Bartoniano medio-Priaboniano tardío (Olivero y Malumián, 1999).

La Formación Cerro Colorado consta de una sucesión grano-estrato creciente de $935 \mathrm{~m}$, que se reconoce desde la playa al sur del cabo José hasta las inmediaciones del abandonado puesto José hacia el norte. El contacto con la subyacente Formación Leticia es una discordancia parcialmente cubierta (ver 3.2.1), al igual que el contacto de techo con la Formación Puesto José. Se describe un perfil continuo en la costa SE del cabo José (Perfil SE, Fig. 7), dividido en dos secciones: una inferior de $c a .600 \mathrm{~m}$ de arreglo grano-estrato creciente caracterizada por intercalaciones de arenisca-fangolita, y una sección superior $(356 \mathrm{~m})$, dominada por arenisca y caracterizada por intercalaciones de paquetes grano-estrato crecientes y paquetes de base erosiva y geometría lenticular grano-estrato decrecientes. 


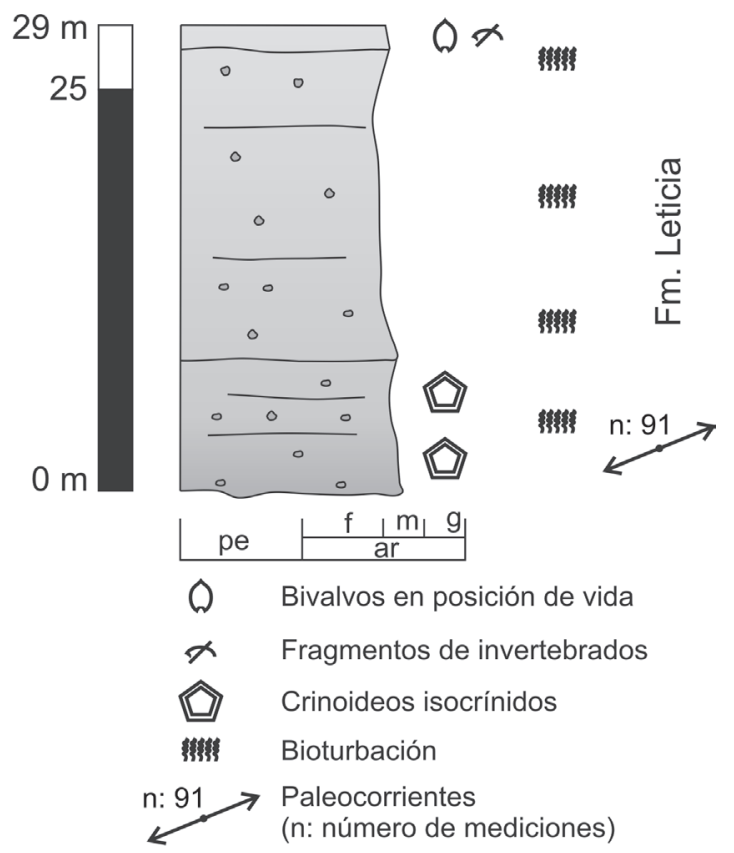

FIG. 6. Columna esquemática de la Formación Leticia en el afloramiento sur de la punta Ainol. Las paleocorrientes corresponden a mediciones sobre pelmas de crinoideos orientadas por corrientes. La escala granulométrica es: pe: pelita; ar: arenisca; f: fina; m: mediana; g: gruesa.

La sección inferior comprende $95 \mathrm{~m}$ de pelita gris oscura en la base, cubiertos por paquetes granoestrato crecientes de delgados bancos de arenisca y niveles pelíticos intercalados. Los paquetes varían entre $20 \mathrm{~m}$ de espesor cerca de la base de la sección, y $40 \mathrm{~m}$ hacia el techo.

La sección superior del Perfil SE está compuesta de paquetes de base erosiva grano-estrato decrecientes, formados por capas de arenisca fina de hasta $1 \mathrm{~m}$ de espesor, que en conjunto constituyen geometrías sigmoidales perpendiculares a las direcciones de paleocorrientes (Fig. 8). Los paquetes tienen una potencia que varía entre 5 y $30 \mathrm{~m}$, y se intercalan con sucesiones grano-estrato crecientes de 20 a $40 \mathrm{~m}$ de espesor constituidas por bancos delgados y medianos de arenisca fina y arenisca muy fina-fangolita.

Mediante un banco guía individualizable tanto en el campo como en fotografías aéreas se equiparan niveles del Perfil SE con los de dos perfiles anexos hacia el noroeste siguiendo la línea de costa (Perfil Medio y Perfil NO; Figs. 2 y 7). El Perfil NO se compone de una sucesión grano-estrato creciente cubierta de paquetes grano-estrato decrecientes, y culmina con $83 \mathrm{~m}$ de fangolita gris con intercalaciones de arenisca fina muy indurada y abundantes bivalvos, marcando el techo de la Formación.

Los arreglos de facies en la sección inferior del Perfil SE, con mayor contenido de fangolita, incluyen arenisca fina maciza con escasa laminación cruzada, y ocasionales lentes basales de arena mediana a gruesa y fragmentos de conchillas. Los bancos no superan en general el metro de espesor y tienen geometría tabular con bases netas y marcas de base. Los niveles pelíticos, de pocos centímetros a $2 \mathrm{~m}$ de espesor suelen contener concreciones de pocos centímetros de diámetro. En la sección superior del Perfil SE los paquetes grano-estrato decrecientes se componen de bancos de hasta $1 \mathrm{~m}$ de espesor de arenisca fina maciza y con laminación paralela, estructuras de deformación por carga, restos de vertebrados y lentes basales de granulometría gruesa con fragmentos de valvas. Los paquetes grano-estrato crecientes incluyen bancos tabulares a lenticulares de arenisca fina de hasta $1,5 \mathrm{~m}$ de espesor, con bases de arenisca mediana y laminación paralela. Estos paquetes contienen aislados niveles de pliegues sinsedimentarios (Fig. 9).

Las capas de la Formación Cerro Colorado tienen rumbos muy variables a lo largo de la costa, entre $\mathrm{N} 75^{\circ}$ y N130 $0^{\circ}$, con manteos que gradualmente decrecen de $50^{\circ} \mathrm{N}$ en la base, a $30^{\circ} \mathrm{N}$ cerca del techo, aumentando nuevamente a $c a \cdot 40^{\circ} \mathrm{N}$ cerca del contacto con la formación suprayacente (Fig. 2).

Fósiles. Los únicos ejemplares de macrofauna recuperados son Panopea sp. en posición de vida en el techo de la sección inferior pelítica del Perfil $\mathrm{SE}$, además de otros bivalvos indeterminados; crinoideos isocrínidos en posición de vida en el Perfil $\mathrm{NO}$; $y$ abundantes bivalvos indeterminados retransportados en el techo del Perfil NO (Fig. 7). En esta última localidad Furque y Camacho (1949) mencionan Venus policarpiana y algunos Lithofaga sp. Se hallaron abundantes fragmentos retrabajados de moluscos, principalmente bivalvos y gastrópodos, en las bases de capas de arenisca en todo el perfil. Finalmente, fragmentos de huesos se recuperaron de las facies lenticulares de mayor granulometría en la sección superior del Perfil SE (Fig. 7), donde anteriormente se hallaron restos óseos probablemente de cetáceos (Olivero y Malumián, 1999).

Las trazas fósiles reconocidas en las sucesiones grano-estrato decrecientes incluyen Diplocraterion y Helminthorhaphe, mientras que en las sucesiones grano-estrato crecientes se identificaron abundantes Ophiomorpha rudis, Tasselia y pocos Zoophycos. 


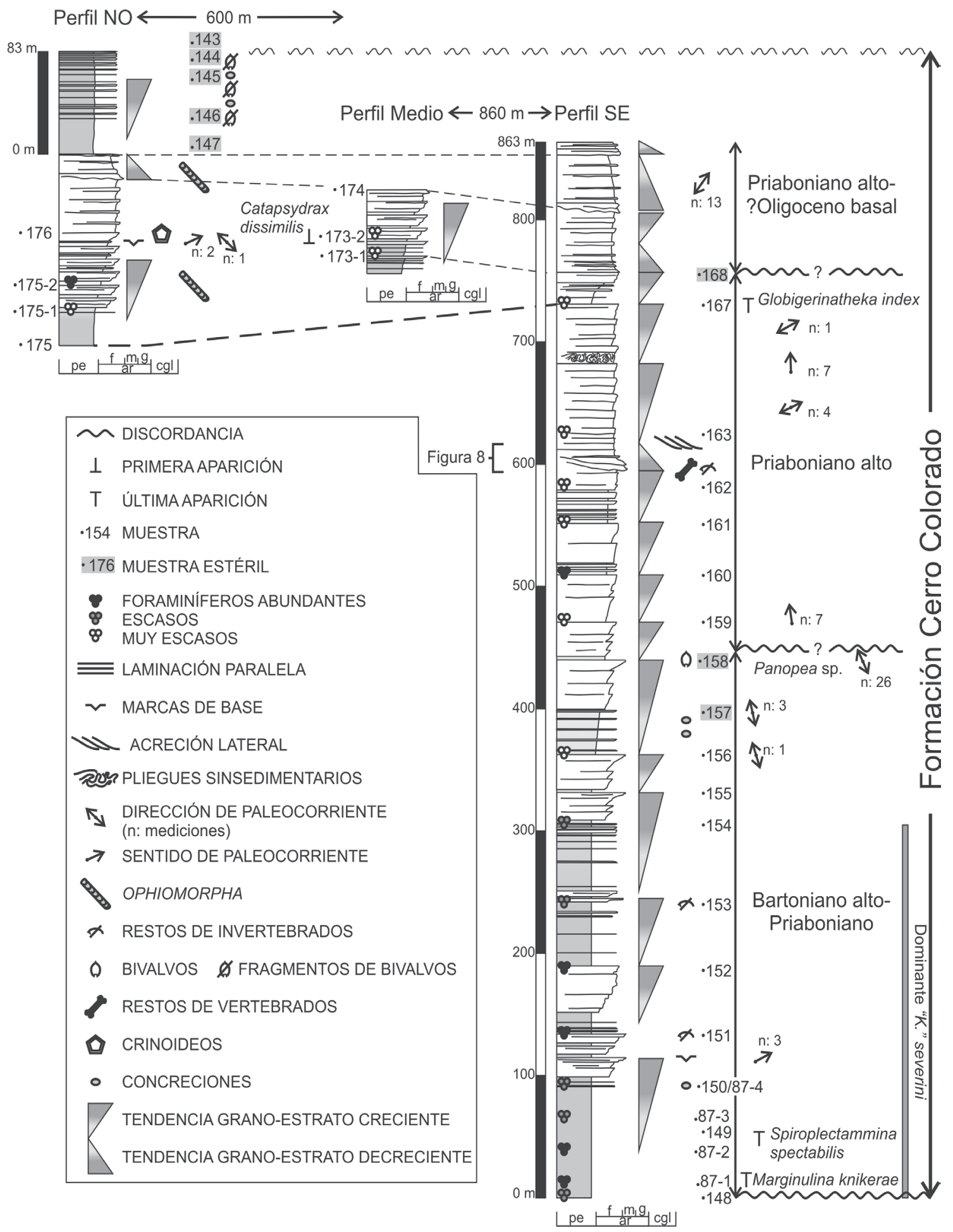

FIG. 7. Perfiles columnares de la Formación Cerro Colorado ilustrando litología, principales rasgos sedimentarios, posición de las muestras, y edad de las secciones individualizadas en el texto. Se indican datos de primera y última aparición de algunos marcadores bioestratigráficos, así como las especies dominantes por tramos. Ver ubicación en la figura 2. La escala granulométrica es: pe: pelita; ar: arenisca; f: fina; m: mediana; g: gruesa; cgl: conglomerado. 

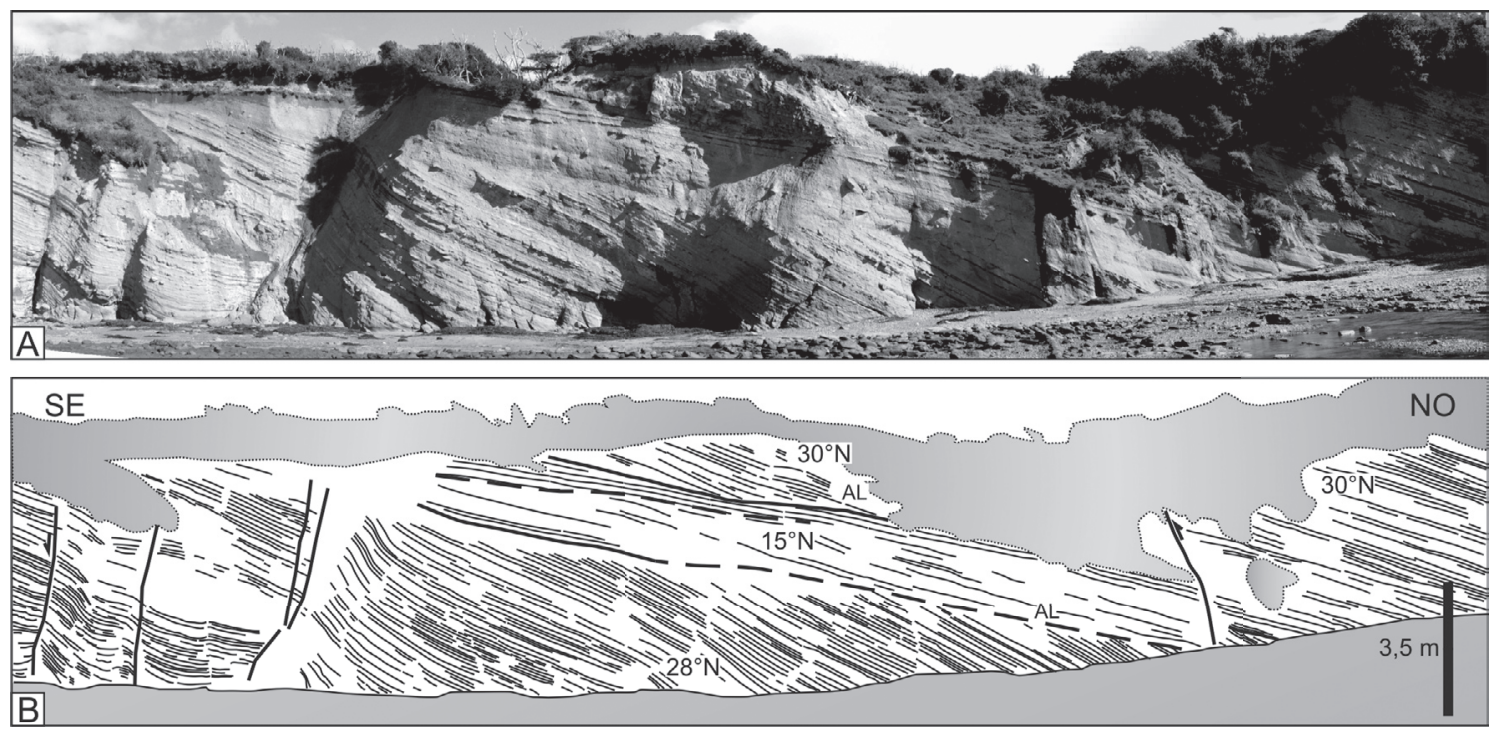

FIG. 8. Paquetes grano-estrato decrecientes de la Formación Cerro Colorado, en la parte sur del cabo José. Ver figura 7 para ubicación en el perfil. Nótese las superficies de truncación erosiva traslapadas por paquetes de arenisca con geometrías sigmoidales. Las geometrías sigmoidales son perpendiculares a las paleocorrientes y se interpretan como acreción lateral (AL) producto de la migración lateral de canales (barras de punta). Se indican los manteos promedio de cada paquete. No se reconoce un decrecimiento gradual del manteo hacia el NO.

Microfósiles. Entre las muestras 148 a 167 (Fig. 7) se diferencian dos conjuntos de foraminíferos: el inferior, entre las muestras 148 a 154, y el superior, 159 a 167; ambos separados por un tramo estéril de un centenar de metros que comprende las muestras entre 155 y 158 inclusive. Sólo se hallaron coprolitos en la 156. En el conjunto inferior se reconocieron los siguientes foraminíferos bentónicos:

'Kolesnikovella' severini (Cañón y Ernst), dominante; Anomalinoides sp.; Cibicidoides truncanus (Gümbel); Duquepsammina cubensis (Palmer); Gyroidinoides octocameratus (Cushman y Hanna); Heterolepa sp.; Lenticulina alatolimbata (Gümbel); Marginulina knikerae (Cañón y Ernst); Nonionella cf. N. stainforthi (Hofker); Parafrondicularia sp.; Pullenia eocenica (Cushman y Siegfus); Reticulophragmium sp.; Spiroplectammina spectabilis (Grzybowski); Stilostomella sp.; Uvigerina maynei (Finlay); acompañados por el planctónico Globigerinatheka index (Finlay).

Este conjunto está dominado por morfotipos infaunales. En una muestra representativa (87-4) del tramo 148 a 87-4 de mayor contenido de pelitas, sobre 300 ejemplares los morfotipos infaunales conforman el $70 \%$, integrados principalmente por ' $K$.' severini (40\%), S. spectabilis (18\%), y $U$. maynei (10\%). Los aglutinados conforman el $20 \%$ y los planctónicos alcanzan sólo al 5\%. El amplio dominio de morfotipos infaunales indica un fondo blando; el muy bajo porcentaje de planctónicos y el pequeño porte de sus conchillas, ambientes someros y desconexión con el mar abierto. Los últimos registros de S. spectabilis y de M. knikerae caracterizan bioestratigráficamente al conjunto.

El conjunto superior, entre las muestras 159167, (ca. $260 \mathrm{~m}$ de areniscas finas) se caracteriza por 'K. 'severini, Reticulophragmium sp., Anomalinoides sp. y Bulimina alsatica (Cushman y Parker). Contiene muy escasos foraminíferos planctónicos, y el último registro de G. index en la muestra 167, cuya última aparición mundial está calibrada en 34,30 Ma, que correlaciona el tramo con el miembro CCd.

En el tramo de las muestras 173-1 a 174 en el Perfil Medio, la aparición de Catapsydrax dissimilis (Cushman y Bermúdez) junto a Subbotina angiporoides (Finlay) caracteriza la asociación de foraminíferos planctónicos, que aumentan en porcentaje $(10 \%)$ respecto al tramo equivalente en el Perfil SE. La dominancia de 'K.' severini y 

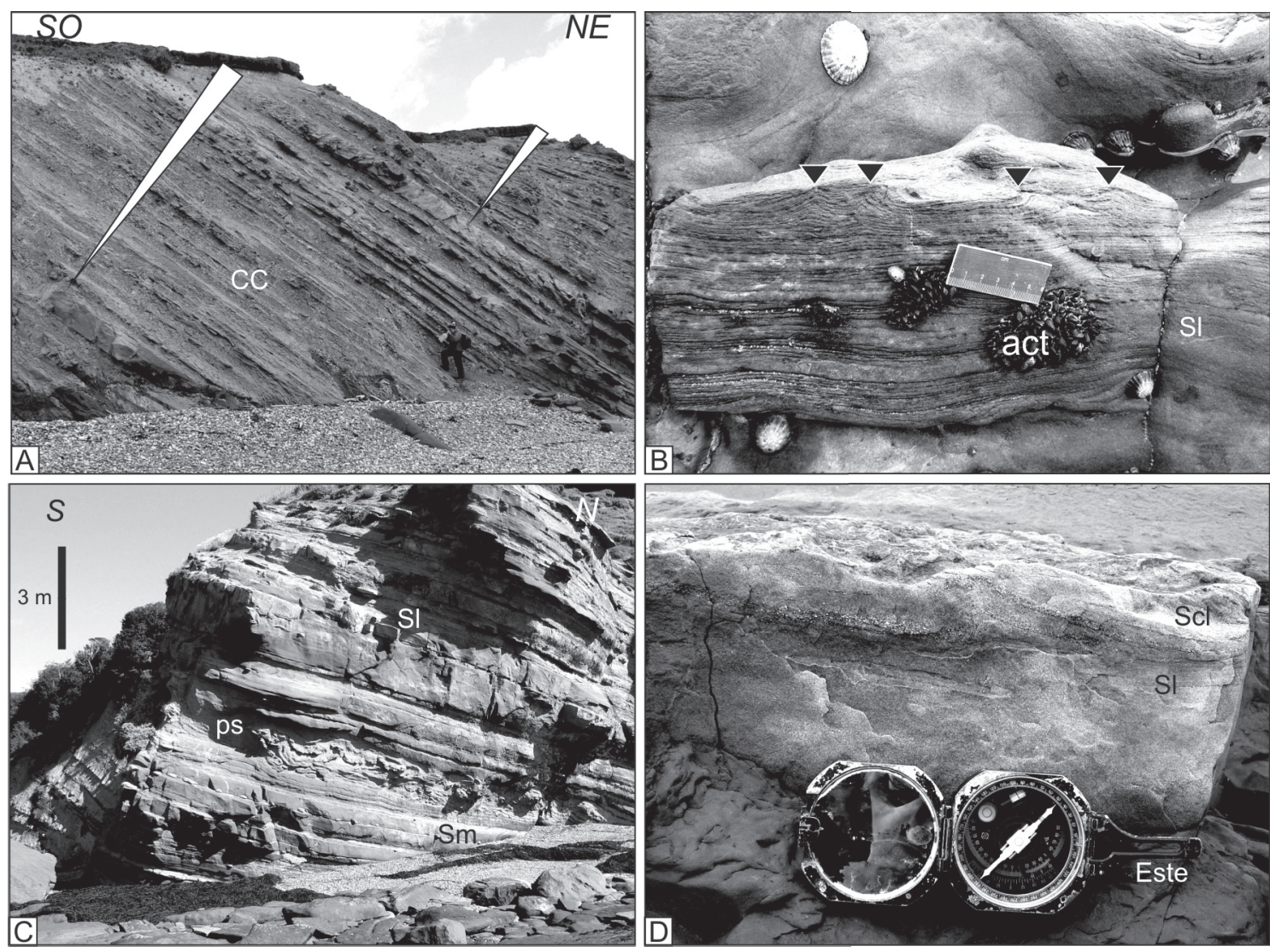

FIG. 9. Detalle de las facies reconocidas en la Formación Cerro Colorado (CC). A. Aspecto de los paquetes grano-estrato crecientes cerca del techo de la formación, en el perfil NO (ver Figura 7); B. Areniscas con laminación paralela (SI) deformada por carga (triángulos negros). Las manchas oscuras son bivalvos actuales (act); C. Intercalaciones de bancos de arenisca maciza (Sm) y arenisca con laminación (SI), y niveles de plegamiento sinsedimentario (ps); D. Detalle de un banco de arenisca con base erosiva, laminación paralela y laminación entrecruzada (Scl) en la sección inferior del perfil SE.

Reticulophragmium $\mathrm{sp}$. dentro de una asociación de baja diversidad y muestras con sólo foraminíferos aglutinados, caracteriza la asociación de bentónicos. Estos niveles con sólo aglutinados indican condiciones de disolución y depositación bajo la línea de compensación de la calcita, y entre los aglutinados las formas como Reticulophragmium, con paredes complejas, indican condiciones de profundidad.

El tramo que comprende las muestras 175-176 del Perfil NO tiene sólo foraminíferos aglutinados (muestra 175) y los planctónicos Chiloguembelina ototara (Finlay), Catapsydrax spp. y S. angiporoides. El bentónico más común es 'K.' severini, y entre los pocos restantes se destaca una especie muy característica: Proxifrons whaingaroica (Stache).

El tramo 147 a 143 es estéril o de muy bajo conte- nido en foraminíferos aglutinados indeterminables, salvo la muestra 146 que contiene coprolitos. El considerable espesor de este tramo $(83 \mathrm{~m})$ sugiere la interposición de una discordancia entre la Formación Cerro Colorado y la suprayacente Formación Puesto José.

Correlación. El tramo inferior del Perfil SE de la Formación Cerro Colorado, que comprende el conjunto inferior de foraminíferos, contiene los últimos registros de $M$. knikerae y $S$. spectabilis característicos del miembro inferior de la Formación en su localidad tipo. En especial, el último registro de la primera especie es un marcador del techo del piso Cameroniano de Natland et al. (1974). Un tramo estéril (muestras 157-158) separa la sección inferior de la superior del Perfil SE, que contiene la última aparición de $G$. index, y es correlacionable con el 
miembro superior de la formación. No se reconocen niveles equivalentes a los miembros $\mathrm{CCb}$ y CCc del área tipo de la formación.

La ausencia de foraminíferos en la muestra 168 (nivel $750 \mathrm{~m}$ del Perfil SE) sugiere algún tipo de discontinuidad, sobre la cual se apoyan niveles con una mayor proporción de arena y facies canalizadas, y con escasez o ausencia de pelitas, en contraposición con la sucesión inferior. Además, el porcentaje de foraminíferos planctónicos aumenta en los perfiles Medio y NO, equiparables a la sección superior al nivel $750 \mathrm{~m}$ del Perfil SE. Esto podría implicar un cambio de ambiente deposicional, marcado por una discordancia menor correspondiente al nivel de la muestra 168. El entorno de la muestra 143, por encima de un tramo estéril (147-143) se interpreta como una discordancia que se correlaciona tentativamente con la reconocida debajo de la Formación Tchat-chii del Oligoceno basal (Malumián, 1988; Malumián y Olivero, 2006), y que se asigna al contacto entre las formaciones Cerro Colorado y Puesto José. La ausencia de G. index por encima de la muestra 167 y la primera aparición de $C$. dissimilis en el tramo 173-1 a 174 y de Ch. otorara en el 175-176, sustenta una edad próxima al límite Eoceno-Oligoceno para la discordancia.

Paleoambiente. El bajo contenido de foraminíferos planctónicos y en general los bentónicos indican ambientes de plataforma interna o con comunicación restringida con el mar abierto, con condiciones particulares en los diferentes tramos que han sido detalladas arriba. Se interpreta la Formación Cerro Colorado como depósitos de flujos gravitatorios en un sistema progradante, acumulados en un depocentro geográficamente aislado de la circulación de aguas en mar abierto. Los paquetes grano-estrato crecientes se interpretan como depósitos de lóbulos turbidíticos, mientras que los paquetes grano-estrato decrecientes reconocidos en la sección superior, constituyen depósitos de canales y albardones con elevadas tasas de sedimentación. Evidencia de depósitos canalizados son las superficies erosivas de gran escala en la base de cada paquete, reconocidas en fotografías aéreas a lo largo de $2 \mathrm{~km}$ en algunos casos, y los conjuntos de bancos de arenisca con geometría de barras de punta, producto de la migración lateral de los canales.

La relativa profundización del ambiente indicada por la aparición de foraminíferos planctónicos en los perfiles Medio y NO es atribuible a un aumento de subsidencia coincidente con la carga tectónica debida a la actividad en la faja corrida y plegada hacia el límite Eoceno-Oligoceno, evidenciada asimismo en el techo de la Formación Cerro Colorado y en la Formación Tchat-chii en el margen externo de la subcuenca y en la antefosa (Fig. 10; Malumián y Olivero, 2006; Torres Carbonell et al., 2008a; Capítulo 6).

\subsubsection{Formación Puesto José (nom. nov.). Rupe- liano-? Aquitaniano. 33,90-?20,43 Ma}

Se propone el nombre de Formación Puesto José a la sucesión de fangolita con intercalaciones de arenisca expuesta en el acantilado y restinga entre el puesto José y la bajada del puesto La Chaira. Asimismo, se incluye la sucesión de fangolita y arenisca aflorante al SE y NO del cabo Malengüena por la similitud de litofacies y edad estimada sobre la base de sus foraminíferos. El nombre de la formación deriva del antiguo puesto ganadero perteneciente a la Estancia Policarpo, actualmente abandonado y ubicado en cercanías de la base del perfil tipo (Fig. 2).

Descripción del perfil tipo y espesor. El perfil tipo (Figs. 2 y 11) de la Formación Puesto José se sitúa en el acantilado y restinga entre las inmediaciones del puesto José $\left(54^{\circ} 34^{\prime} \mathrm{S} ; 6^{\circ} 06^{\circ} \mathrm{O}\right)$ y la

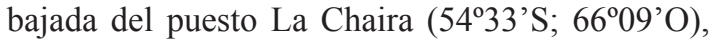
donde alcanza $c a .1 .600 \mathrm{~m}$ de espesor. La base de la Formación Puesto José se encuentra parcialmente cubierta, y no se logra identificar una superficie de contacto neto entre esta formación y la subyacente Formación Cerro Colorado, aunque se infiere una discordancia (ver 3.2.2). El techo de la Formación Puesto José corresponde a una discordancia erosiva que subyace a la Formación Malengüena (ver 3.2.4), expuesta a pocos metros al norte de la bajada del puesto La Chaira, y en la parte norte de la punta Isleta. La discordancia se manifiesta también en el cabo Malengüena.

Se subdivide al perfil tipo en una sección inferior de $370 \mathrm{~m}$ de pelita gris maciza; una sección media de $655 \mathrm{~m}$ de fangolita gris con intercalaciones de arenisca fina y una sección superior grano-estrato creciente de $575 \mathrm{~m}$ de fangolita gris con intercalaciones de arenisca fina y mediana.

Las intercalaciones de arenisca de la sección media conforman bancos tabulares y lenticulares de pocos centímetros de espesor (Fig. 12). Los bancos de arenisca de la sección superior son tabulares de base neta y algunos lenticulares de base erosiva, de hasta medio metro de espesor y más frecuentes 


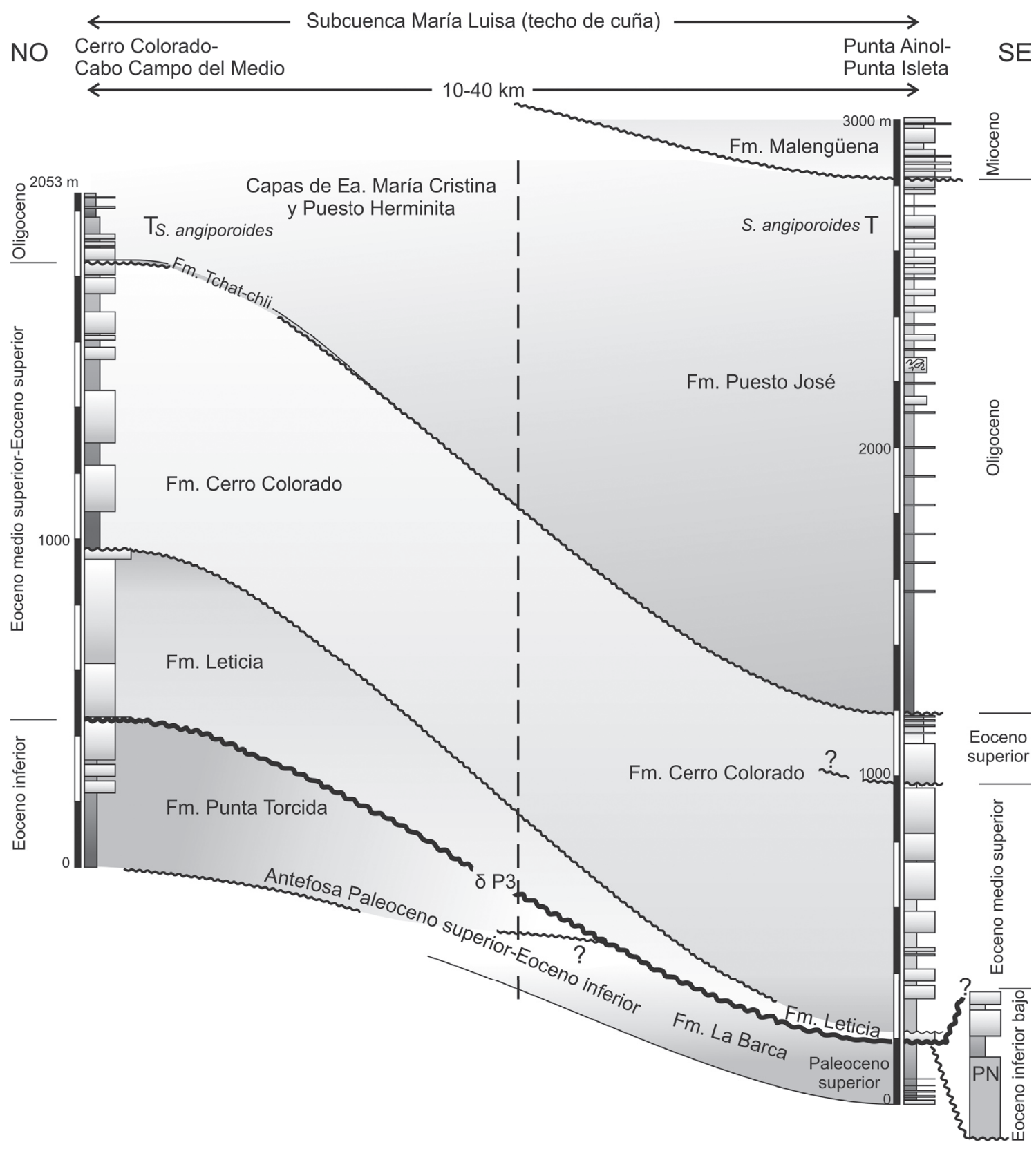

FIG. 10. Correlación de los depósitos de la antefosa paleocena superior-eocena inferior y la subcuenca María Luisa (separadas por la discordancia P3); entre los sectores de la punta Isleta-punta Ainol, y el cerro Colorado-cabo Campo del Medio. Los perfiles de este último sector son modificados de Olivero y Malumián (1999), y Malumián y Olivero (2006). PN: Formación Punta Noguera. Nótese el importante acuñamiento del Oligoceno hacia el límite norte de la subcuenca María Luisa, evidenciado por el último registro de $S$. angiporoides. Se ilustra la ubicación aproximada del sistema transformante Fagnano (línea interrumpida), cuyo efecto es posterior al desarrollo de la subcuenca.

hacia el techo. En la base de la sección superior y en su parte media se reconocen pliegues sinsedimentarios de gran escala (hasta $50 \mathrm{~m}$ de espesor) de aparente vergencia noreste (Fig. 12H). El techo de la sección superior consiste de $c a$. $20 \mathrm{~m}$ de bancos tabulares a lenticulares de arenisca mediana a fina con conglomerado fino basal. Los bancos individuales promedian los $0,4 \mathrm{~m}$ de espesor y alcanzan un máximo de $1 \mathrm{~m}$. 


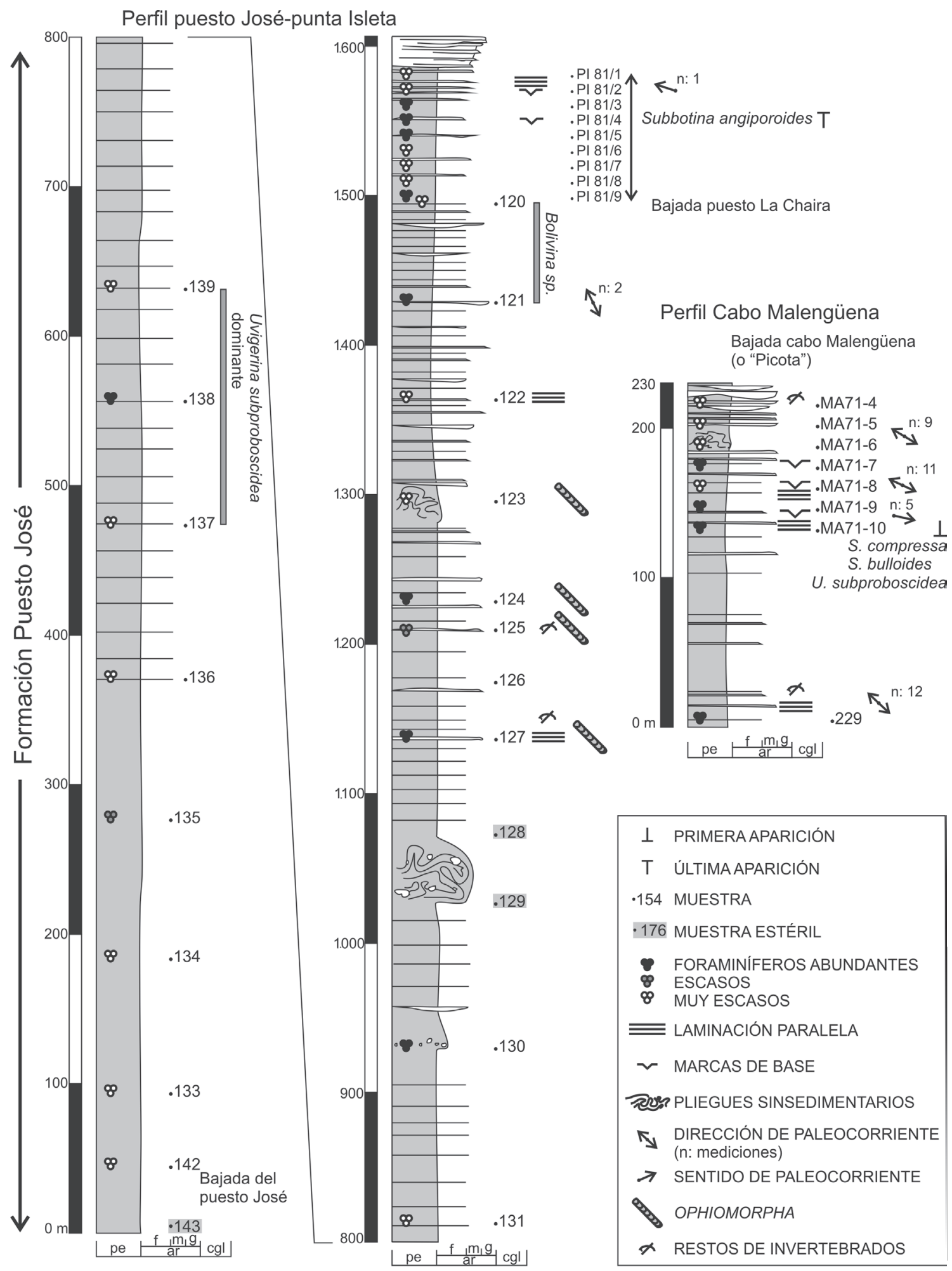

FIG. 11. Perfil tipo de la Formación Puesto José. Se ilustran la litología, principales rasgos sedimentarios, y posición de las muestras. Se indican primera y última aparición de algunos marcadores bioestratigráficos, así como las especies dominantes por tramos. La ubicación del perfil entre el puesto José y la punta Isleta se indica en la figura 2. El perfil del cabo Malengüena se ubica en la figura 13. 


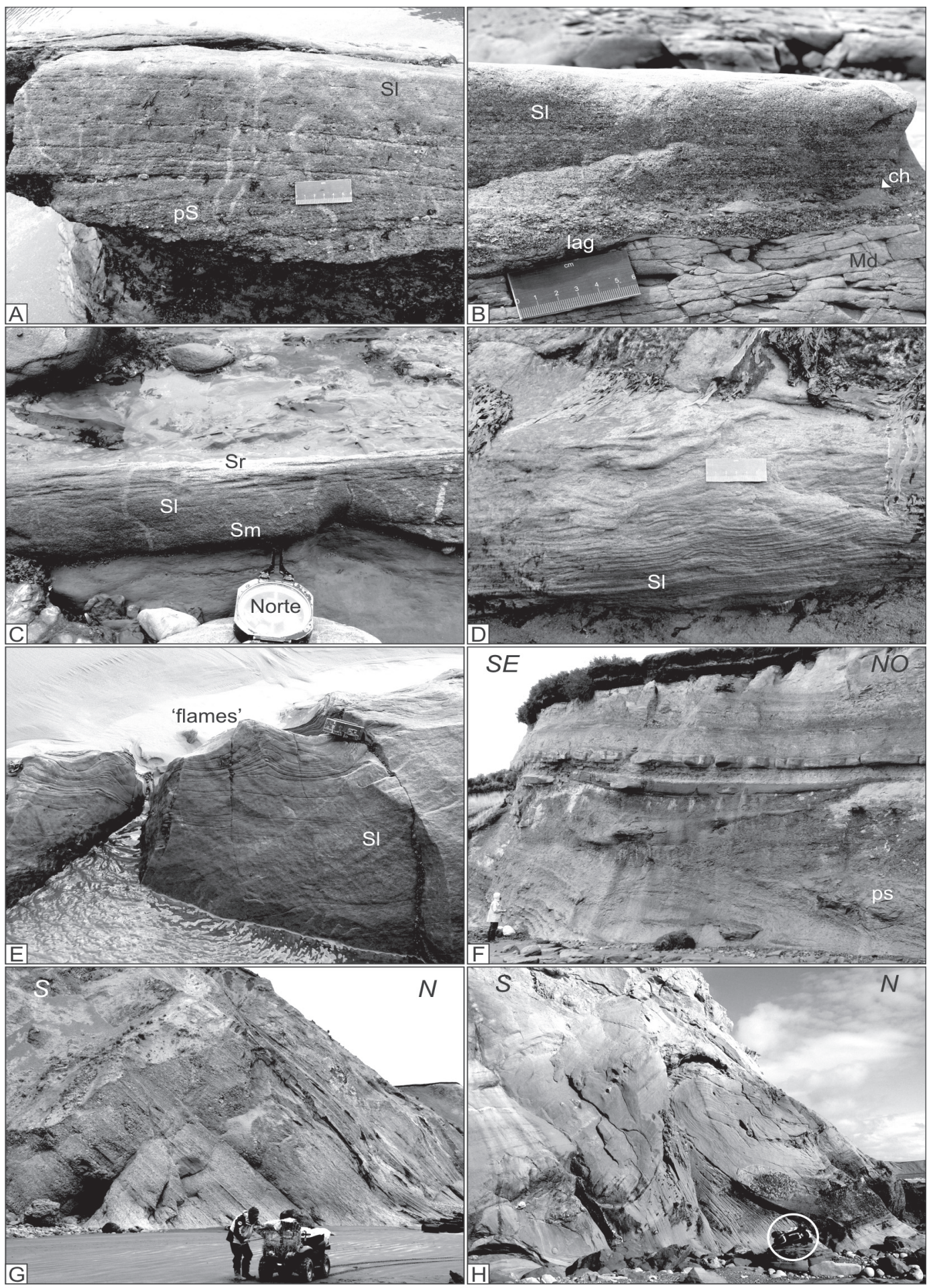

FIG. 12. Facies reconocidas en la Formación Puesto José. A-C. Bancos de arenisca de base erosiva intercalados en fangolita (Md), con conglomerado fino (pS), lentes residuales bioclásticos (lag), intraclastos de arcilla (ch), arenisca maciza (Sm), arenisca con laminación paralela (SI) y ondulitas de corriente (Sr); D-E. Arenisca con laminación paralela (SI) y deformación por carga ('flames'); F. Bancos de arenisca fina con geometrías lenticulares y niveles con plegamiento sinsedimentario (ps) en el perfil del cabo Malengüena; G. Aspecto de las delgadas intercalaciones de arenisca fina y fangolita en el perfil tipo, cerca de la bajada del puesto La Chaira; H. Pliegue sinsedimentario de gran escala con aparente vergencia N. 
Las facies más notables en la sección media incluyen conglomerado matriz-sostén con matriz fangolítica, intraclastos de arcilla y clastos flotantes de arenisca concrecionada que no superan los $10 \mathrm{~cm}$ de diámetro. Las areniscas son macizas o con laminación paralela, y las fangolitas macizas. En la sección superior las bases de conglomerado fino de los bancos individuales tienen fragmentos de valvas con disolución parcial y clastos con parcial reemplazo de glauconita; las areniscas son macizas o con gradación normal, laminación paralela a veces deformada, ondulitas de corriente y estructuras de deformación por carga, y las fangolitas son macizas (Fig. 12A-E). Son comunes las estructuras de 'mezcla' o inyecciones de pelita en las bases de bancos de arenisca, interpretadas como sismitas, o calcos de carga muy deformados. La bioturbación en las areniscas es moderada y consiste principalmente de excavaciones con pared asignables a Ophiomorpha. La composición petrográfica de las areniscas y conglomerados finos es principalmente de feldespato (dominante plagioclasa), cuarzo, fragmentos de esquisto y volcanita.

La Formación Puesto José hacia el SE del cabo Malengüena (Perfil Cabo Malengüena; Figs. 11 y 13), consiste de una sucesión grano-estrato creciente de $230 \mathrm{~m}$ de espesor mínimo con base cubierta y techo expuesto. Esta sucesión está dividida en dos secciones, inferior y superior, que difieren en facies y granulometría. La sección inferior comprende $c a$. $200 \mathrm{~m}$ de pelita gris, con intercalaciones de delgados bancos tabulares de arenisca muy fina a fina que se hacen más frecuentes hacia el techo. Hacia la parte superior de la sección se reconocen lentes de arenisca mediana a gruesa y fina, y pliegues sinsedimentarios de escala media (Fig. 12F). Los bancos de arenisca tienen marcas de base y conglomerados finos basales con abundantes fragmentos de valvas; gradación normal y laminación paralela, y estructuras de deformación por carga.

La sección superior del Perfil Cabo Malengüena $(\mathrm{ca} .30 \mathrm{~m})$ consiste de una sucesión granoestrato creciente de fangolita gris con abundantes intercalaciones de bancos tabulares y lenticulares de arenisca. Las facies incluyen conglomerado basal con clastos tamaño arena gruesa a grava, con abundantes fragmentos de bivalvos y gastrópodos (e.g., Turritella sp.), y arenisca mediana a fina con estructuras sedimentarias similares a las presentes en la sección inferior (Fig. 12A-E). Las areniscas y conglomerados se componen de feldespato, cuarzo, fragmentos de esquisto y volcanita.

Límites y distribución. Lateralmente el extenso afloramiento de la Formación Puesto José está limitado por el borde de la restinga en baja marea y por el techo de los acantilados en el área tipo. La estratificación de la Formación Puesto José tiene rumbos variables a lo largo del perfil, debido al notable alabeo regional de la estructura manifiesto en fotografías aéreas. El rumbo promedio de las capas es $\mathrm{N} 76^{\circ}$, con manteos de 40 a $50^{\circ} \mathrm{NO}$ en el área del puesto José-punta Isleta, mientras que en la sucesión en inmediaciones del cabo Malengüena la orientación promedio es de $\mathrm{N} 96^{\circ}$, con manteos entre $30^{\circ}$ y $10^{\circ}$ al norte.

Fósiles. Los macrofósiles encontrados se limitan a los restos transportados de bivalvos, gastrópodos y equinodermos, entre los que se reconocen algunos ejemplares de Turritella sp. mal preservados, contenidos en las fracciones conglomerádicas. Las trazas reconocidas se limitan a Ophiomorpha rudis, especialmente en los bancos de arenisca de la sección superior del perfil tipo.

Microfósiles. Se hallaron foraminíferos aglutinados y calcáreos, y radiolarios esféricos recristalizados. En el perfil tipo (Fig. 11), el tramo correspondiente a las muestras 143 a 133 contiene sólo foraminíferos aglutinados y se apoya sobre niveles estériles; la muestra 134 contiene foraminíferos planctónicos grandes y la muestra 136, sólo aglutinados. El tramo 137-139 contrasta por sus conchillas calcáreas bien preservadas, y contiene Uvigerina subproboscidea (Haque) dominante, acompañada de:

Anomalinoides orbiculus (Stache); Cibicides sp.; Hoeglundina elegans (d'Orbigny); N. longiscata; Reticulophragmium sp.; Stilostomella sp.; Trifari$n a$ ? sp.; Uvigerina sp.

El tramo 131-122 tiene material bien conservado, con fuerte selección hacia tamaños grandes en la muestra 130, y seleccionados hacia tamaños chicos en la 124; y muestras estériles en los niveles de plegamiento sinsedimentario (128-129). El contenido del tramo es:

Oridorsalis umbonatus (Reuss); Plectofrondicularia awamoana (Finlay); S. angiporoides es el planctónico dominante. 


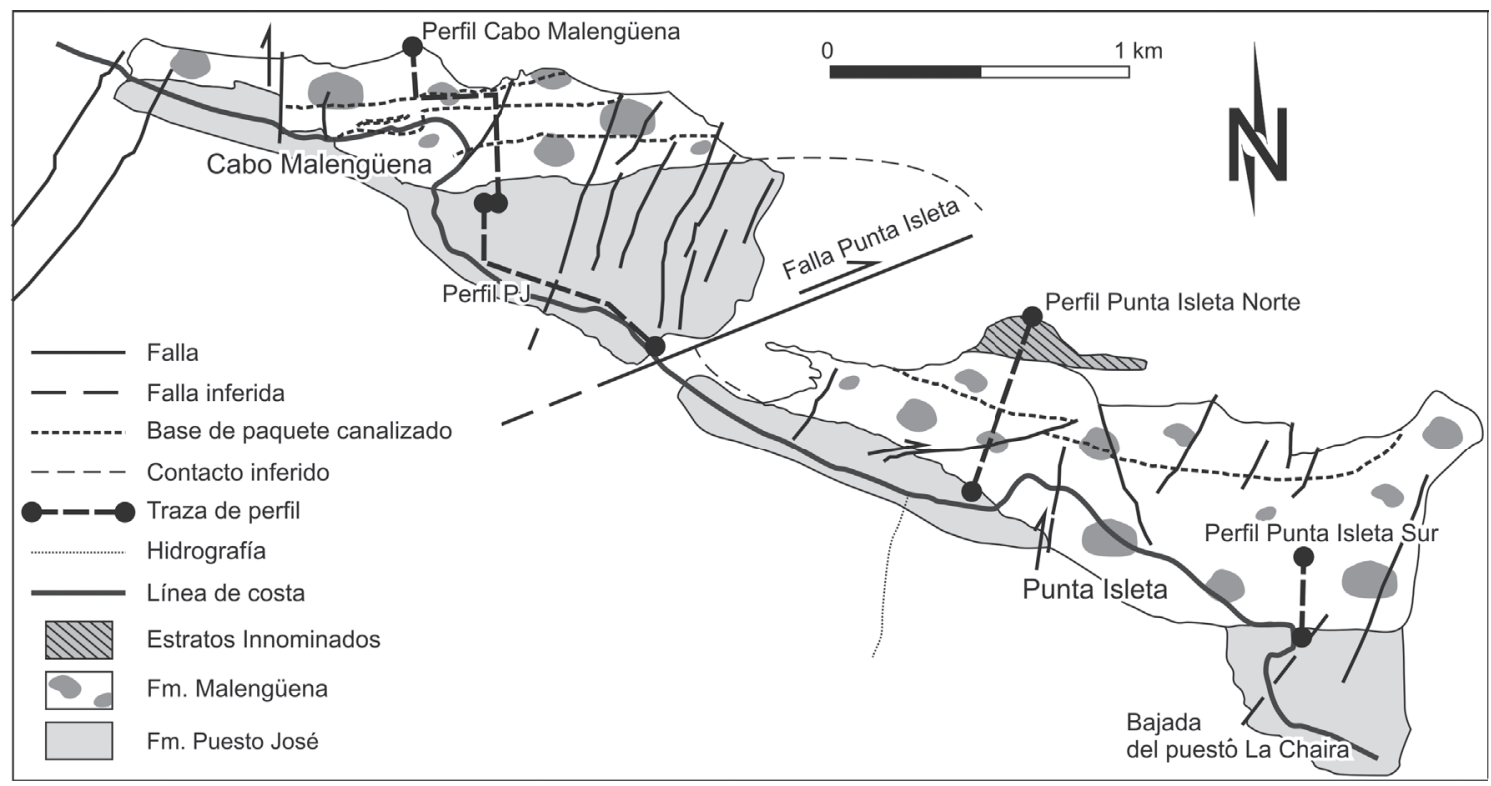

FIG. 13. Mapa geológico de detalle del sector del cabo Malengüena-punta Isleta. Se ilustran las unidades del Oligoceno-?Mioceno, los principales rasgos estructurales, y la distribución de los paquetes canalizados en la Formación Malengüena. Se indica la ubicación de los perfiles de la Formación Puesto José en el cabo Malengüena (Perfil PJ; figura 11) y de la Formación Malengüena (perfiles Punta Isleta Sur, Punta Isleta Norte y Cabo Malengüena, ver figura 14).

El tramo 121-120 señala aguas fértiles por la distintiva abundancia de Bolivina y de radiolarios esféricos, y contiene muy abundante U. subproboscidea y Bolivina sp., acompañada de:

Ammodiscus sp.; Globocassidulina subglobosa (Brady); Martinottiella sp.; Proxifrons inaequalis (Costa); Reticulophragmium sp.; Rhabdammina sp.

El Tramo 81/1 a 81/9 contiene los foraminíferos bentónicos:

Alabamina dissonata (Cushman y Renz); Antarcticella antarctica (Leckie y Webb); Bathysiphon sp.; Bulimina inflata (Seguenza); Globocassidulina cuneata (Finlay); Martinottiella sp.; Plectofrondicularia $\mathrm{sp}$; Trifarina sp.; U. subproboscidea; $U$. maynei.

Foraminíferos planctónicos:

'Praeglobigerinoides' sp.; S. angiporoides; C. dissimilis; Zeaglobigerina labiacrassata (Jenkins).

En el Perfil Cabo Malengüena (Fig. 11) las muestras 229, MA71-10 y MA71-9 contienen una abundante microfauna, entre los foraminíferos planctónicos:

Catapsydrax martini (Blow y Banner); Globigerina praebulloides (Blow); Paragloborotalia nana (Bolli); Sphaeroidinellopsis cf. disjuncta (Finlay); Tenuitella clemenciae (Bermúdez); Z. labiacrassata.

Entre los foraminíferos bentónicos calcáreos dominante $U$. subproboscidea acompañada de:

Anomalinoides sp.; Bolivina sp.; Bulimina sp.; Fissurina fimbriata (Sidebottom); G. subglobosa; Laticarinina pauperata (Parker y Jones); Melonis pompilioides (Fitchell y Moll); Pullenia bulloides (d' Orbigny); Sphaeroidina bulloides (d' Orbigny); Uvigerina sp.

Entre los foraminíferos aglutinados:

Spirosigmoilinella compressa (Matsunaga); Reticulophragmium sp.

Las muestras MA71-4 y MA71-5 contienen conchillas escasas, y su muy buena preservación 
contrasta con la MA71-6 con exclusivas conchillas de aglutinados.

Edad. En especial se destaca la última aparición de S. angiporoides en la muestra PI 81/4, que acota la menor edad de la secuencia del perfil tipo al Oligoceno temprano (30 Ma). Por otra parte 'Preglobigerinoides' sp. se refiere a las formas identificables con el género, pero carentes de aberturas suplementarias, que son abundantes en el Oligoceno 'medio' de las altas latitudes, en el sentido de Spezzaferri (1994).

La sucesión del Perfil Cabo Malengüena carente de $S$. angiporoides sugiere una edad menor a $30 \mathrm{Ma}$, confirmada por los más antiguos registros de $S$. compressa y $S$. bulloides que indican una máxima edad oligocena tardía. Si se considera que la desaparición de Z. labiacrassata en la zona circumantártica ha sido estimada en 27,10 Ma por Huber y Quillévéré (2005), la edad quedaría circunscrita al Chattiano temprano. Sin embargo, según Spezzaferri (1994), el biocrón de Z labiacrassata se encontraría desde el Oligoceno tardío al Mioceno medio temprano, mientras que la existencia de formas muy próximas a $S$. disjuncta sugieren una edad algo menor, próxima al límite Oligoceno-Mioceno.

Correlación. La Formación Puesto José se identifica con las capas de la Estancia María Cristina y del Puesto Herminita por su edad oligocena (Fig. 10) y el muy similar contenido en foraminíferos (Scarpa y Malumián, 2008), y con el 'Glauconítico A' y la 'Margosa Superior' en el subsuelo de la cuenca Austral (cf. Malumián y Olivero, 2006; Malumián et al., 2008b). El Oligoceno en la costa Atlántica comprende sucesiones grano-estrato decrecientes constituidas de bancos de arenisca fina intercalados en fangolita, y fangolita con concreciones calcáreas, de $375 \mathrm{~m}$ de espesor mínimo, depositadas bajo la línea de compensación de la calcita y expuestas parcialmente en el cerro Colorado y la punta Gruesa (Malumián y Olivero, 2006). En el cerro Colorado la sección inferior (Oligoceno basal) corresponde a depósitos probablemente sintectónicos, que rellenan el espacio creado en el sinclinal frontal del anticlinal Campo del Medio (Torres Carbonell et al., 2008a).

Paleoambiente. Los foraminíferos planctónicos son escasos probablemente a causa de la disolución debida a aguas corrosivas. Los foraminíferos bentónicos son de ambientes de plataforma profunda hasta batial superior. La pronunciada selección por tamaños indica acción de corrientes.
Las facies dominadas por fracciones pelíticas y la deformación sinsedimentaria (manifiesta ampliamente en el perfil tipo) apoyan la interpretación de un ambiente de talud deposicional adyacente al margen orogénico de la subcuenca, con una pendiente con componente norte y alta tasa de sedimentación. Los delgados bancos de arenisca fina a muy fina con gradación normal y laminación paralela reconocidos en las secciones inferior y media del perfil tipo se interpretan como turbiditas finas (F8-F9, cf. Mutti, 1992). Los lentes de arenisca con estructuras de corriente (Fig. 12A-E) corresponden al relleno de complejos de canales pandos, más frecuentes hacia el techo de la formación. En conjunto, la sucesión de la Formación Puesto José denota un neto carácter progradante.

Los pliegues sinsedimentarios de gran escala en la base de la sección superior del perfil tipo (Fig. $12 \mathrm{H})$ junto con la mayor proporción de arenisca hacia el techo del perfil, se interpretan como el resultado de una etapa de mayor aporte sedimentario a la cuenca con respecto a las secciones inferior y media. Esta etapa de alta tasa de aporte clástico se correlaciona con un evento tectónico responsable del plegamiento inicial de las capas de la formación (capítulos 5 y 6 ).

\subsubsection{Formación Malengüena (nom. nov.). Chattiano superior-?Mioceno inferior}

Se propone el nombre de Formación Malengüena para la sucesión de conglomerado y arenisca expuesta en la restinga y acantilado de la punta Isleta y del cabo Malengüena, que da el nombre a la formación.

Descripción del perfil tipo y espesor. La sección tipo de la Formación Malengüena incluye la sucesión de $216 \mathrm{~m}$ de conglomerado y arenisca aflorante entre la bajada del puesto La Chaira (54³3'S; 66 $\left.06^{\circ} \mathrm{O}\right)$ y el extremo de la restinga de la punta Isleta $\left(54^{\circ} 32,5^{\prime} \mathrm{S}\right.$; $\left.66^{\circ} 10^{\prime} \mathrm{O}\right)$, y a la sucesión de 123,5 m de arenisca aflorante en el cabo Malengüena entre los puntos $54^{\circ} 32,5^{\prime}$ 'S; 66 ${ }^{\circ} 12^{\prime} \mathrm{O}$ y $54^{\circ} 32,2^{\prime} \mathrm{S}$; $66^{\circ} 12^{\prime} \mathrm{O}$ (Figs. 13 y 14). La base de la formación es la discordancia erosiva sobre las capas de la Formación Puesto José (Fig. 15), mejor expuesta en el sector norte del acantilado de la punta Isleta. La traza de la discordancia en la restinga es también identificable en fotografías aéreas. El techo de la formación está parcialmente expuesto solamente en la restinga de la punta Isleta, y corresponde al contacto aparentemente neto con capas de arenisca innominadas ('Estratos Innomi- 


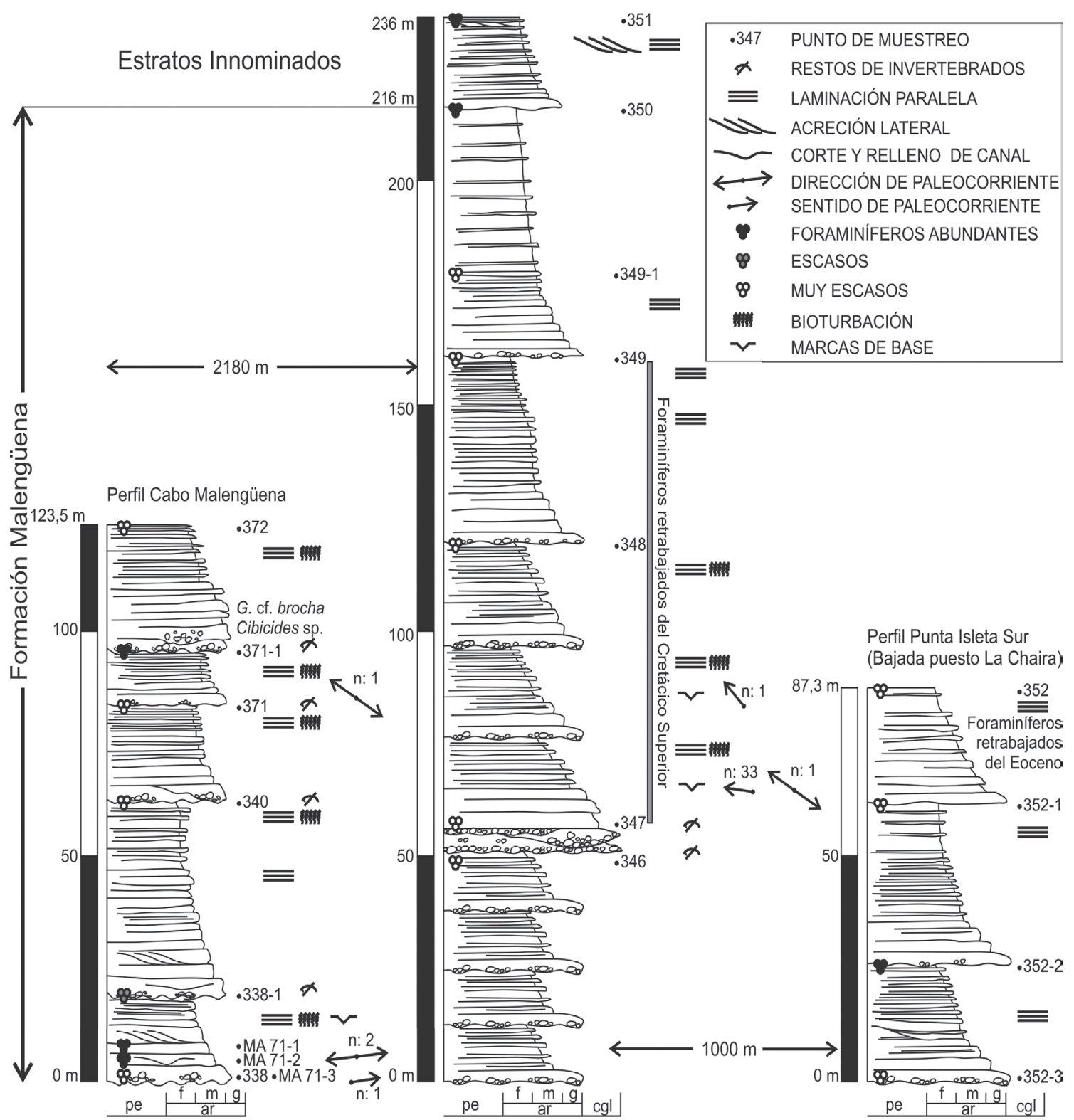

FIG. 14. Perfil tipo de la Formación Malengüena, compuesto entre la punta Isleta Sur y el cabo Malengüena. Se ilustran la litología, principales rasgos sedimentarios, y posición de las muestras. Se indican los foraminíferos y rasgos micropaleontológicos dominantes por tramos. La ubicación de los perfiles individuales se muestra en la figura 13.

nados') aflorantes en el extremo de la restinga en bajamar. La Formación Malengüena se compone de paquetes grano-estrato decrecientes que en la base exponen espesos (1-2 m) lentes de conglomerado grueso a arenisca fina y, hacia el techo, intercalaciones de delgadas capas tabulares de arenisca mediana y fina, bioturbadas.
El Perfil Punta Isleta Sur (Fig. 14), de $87 \mathrm{~m}$ de potencia, se compone de paquetes grano-estrato decrecientes de 25 a $50 \mathrm{~m}$ de espesor, formados por bancos lenticulares de arenisca mediana a fina con conglomerado fino basal, de 0,5 a $1 \mathrm{~m}$ de espesor, y arenisca fina en bancos más delgados hacia el techo de cada paquete. Las areniscas tienen gradación 

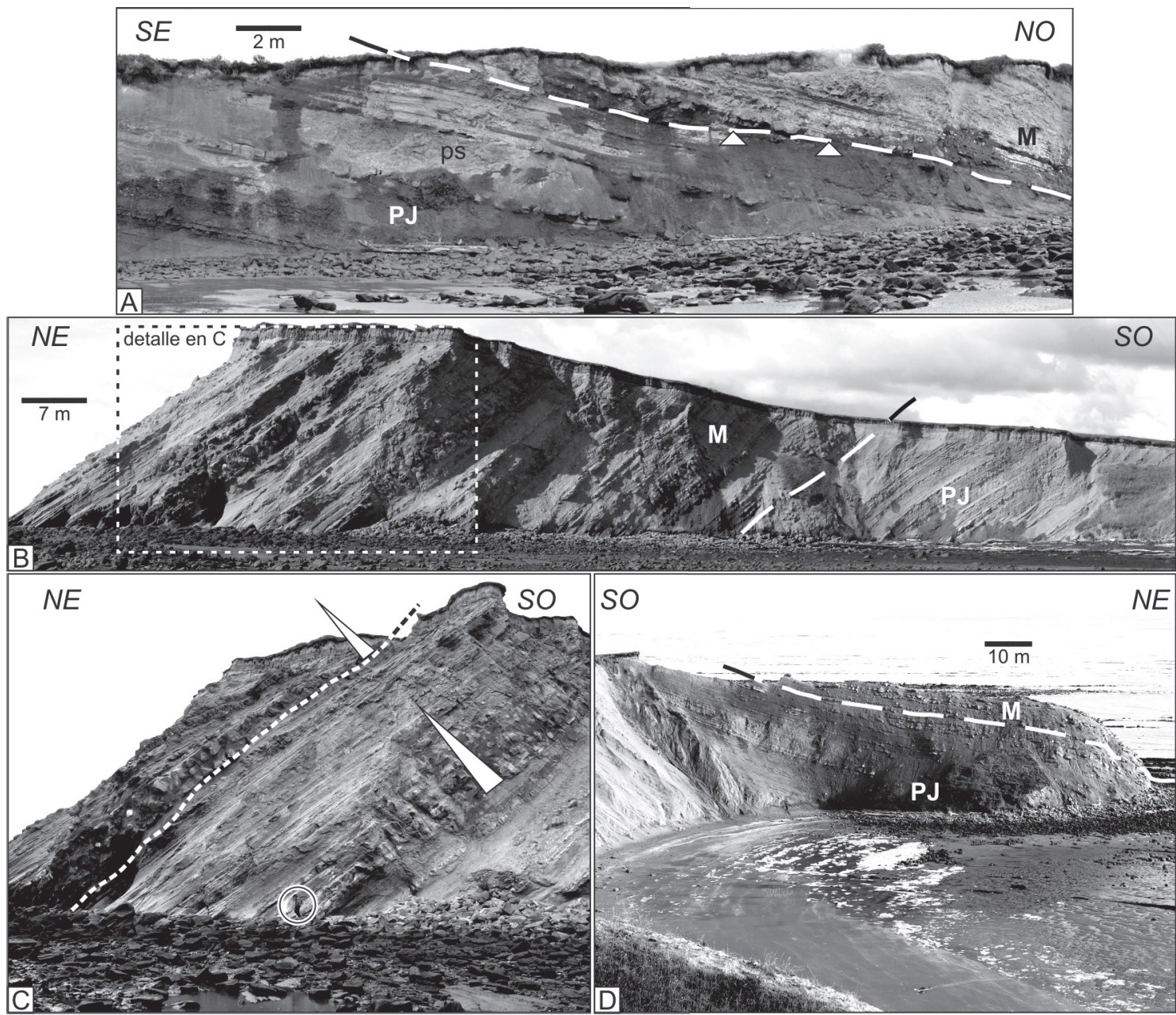

FIG. 15. A. Detalle del contacto discordante (línea discontinua) entre las Formaciones Puesto José (PJ) y Malengüena (M) en el sector SE del cabo Malengüena. Nótese el nivel de pliegues sinsedimentarios (ps) en la Formación Puesto José, y la terminación lateral de capas sobre la discordancia (triángulos); B. Contacto en la punta Isleta norte; C. Detalle de las facies más gruesas de la Formación en la punta Isleta Norte, nótese la superficie erosiva intraformacional, interpretada como la base de un canal que separa dos paquetes granodecrecientes; D. Contacto en el sector de la punta Isleta Sur (bajada del puesto La Chaira).

normal y laminación paralela a veces deformada por carga, con abundantes restos de valvas de moluscos y espinas de equinoideos.

Lateralmente en el Perfil Punta Isleta Norte (Fig. 14), de $216 \mathrm{~m}$, los paquetes grano-estrato decrecientes varían entre 10 y $50 \mathrm{~m}$ y se hacen más espesos hacia el techo. Las facies en el paquete inferior incluyen conglomerado y brecha clasto-sostén muy grueso, con bloques de más de $0,3 \mathrm{~m}$ de diámetro, en lentes de variable espesor y reducida extensión lateral (Figs. 16A y 17A, E); brecha matriz-sostén con clastos angulosos de fangolita; arenisca gruesa a mediana, en parte conglomerádica, con gradación normal a arenisca fina y con laminación paralela; y arenisca fina con gradación normal, laminación paralela y con bioturbación abundante (Fig. 16B, C). Los bancos individuales de arenisca tienen entre 0,9 y menos de $0,3 \mathrm{~m}$ de espesor (Fig. 16B), ocasionalmente con marcas de base. Los paquetes expuestos hacia el techo del perfil tienen facies similares, pero sin conglomerados gruesos. La composición petrográfica comprende abundantes fragmentos de esquisto, plagioclasa, cuarzo y líticos volcánicos minoritarios, y subordinadamente fragmentos de sedimentitas reconocidos sobre todo en las facies más gruesas. Abundan los fragmentos de gastró- 


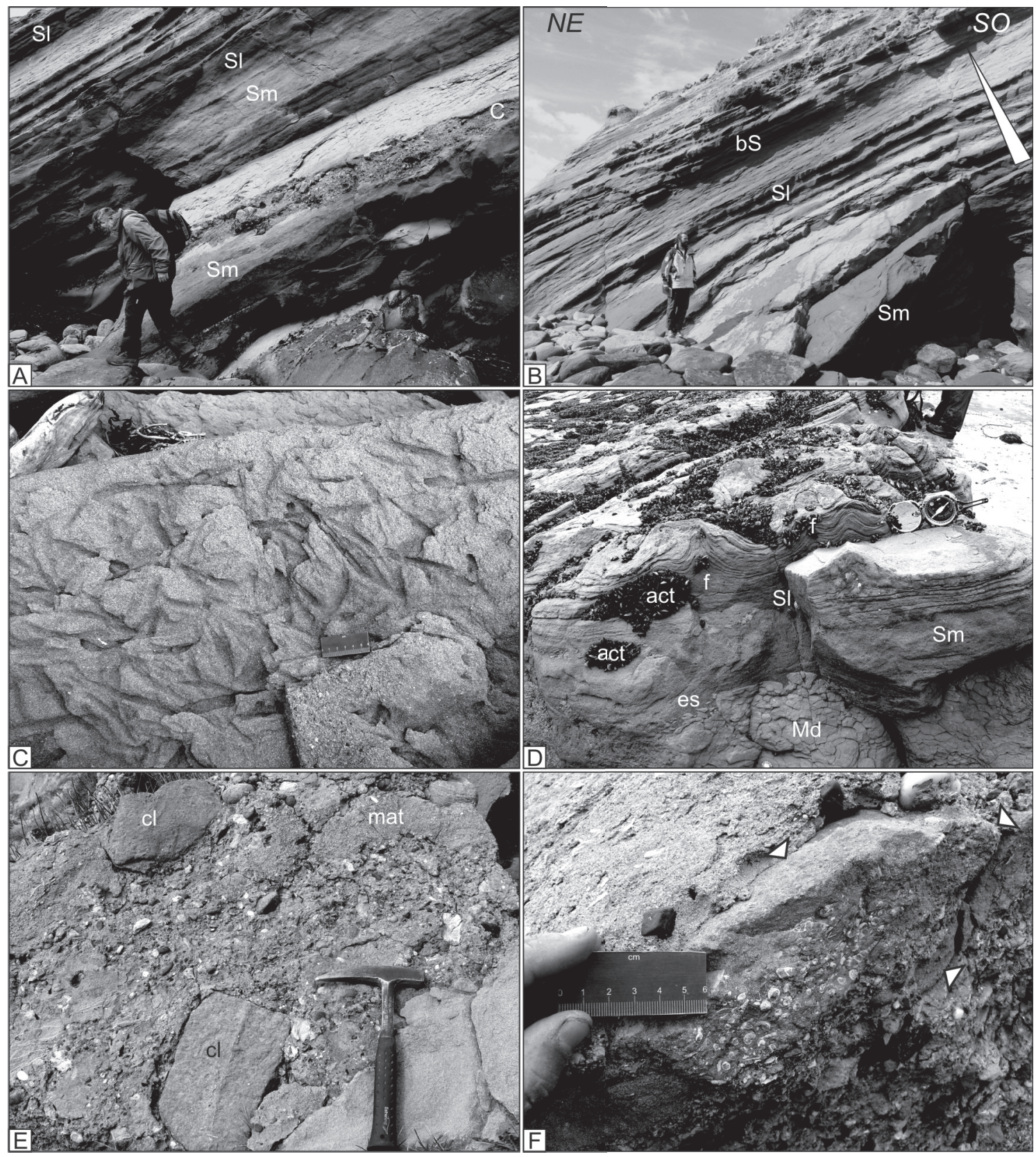

FIG. 16. Facies reconocidas en la Formación Malengüena. A-B. Paquetes grano-estrato decrecientes con conlgomerado (C), arenisca masiva (Sm), arenisca con laminación (SI) y arenisca bioturbada (bS); C. Detalle de la bioturbación en capas de arenisca fina. Vista de techo; D. Banco de arenisca de base erosiva (es) sobre fangolita (Md), con gradación de arenisca masiva a laminada, deformada por carga (f: 'flames'). Las manchas oscuras son bivalvos actuales (act); E. Detalle de conglomerado matriz-sostén (mat: matriz), con clastos (cl) de tamaño bloque; F. Detalle de un clasto de sedimentita fosilífera (delimitado por triángulos) en el conglomerado mostrado en $\mathrm{E}$.

podos (e.g., Turritella sp.), corales, briozoarios y espinas de equinoideos. Los paquetes grano-estrato decrecientes individuales de los perfiles de la punta
Isleta conforman a gran escala geometrías lenticulares de base erosiva (Figs. 13, 15C y 17F), por lo que se interpreta que las facies gruesas corresponden al 


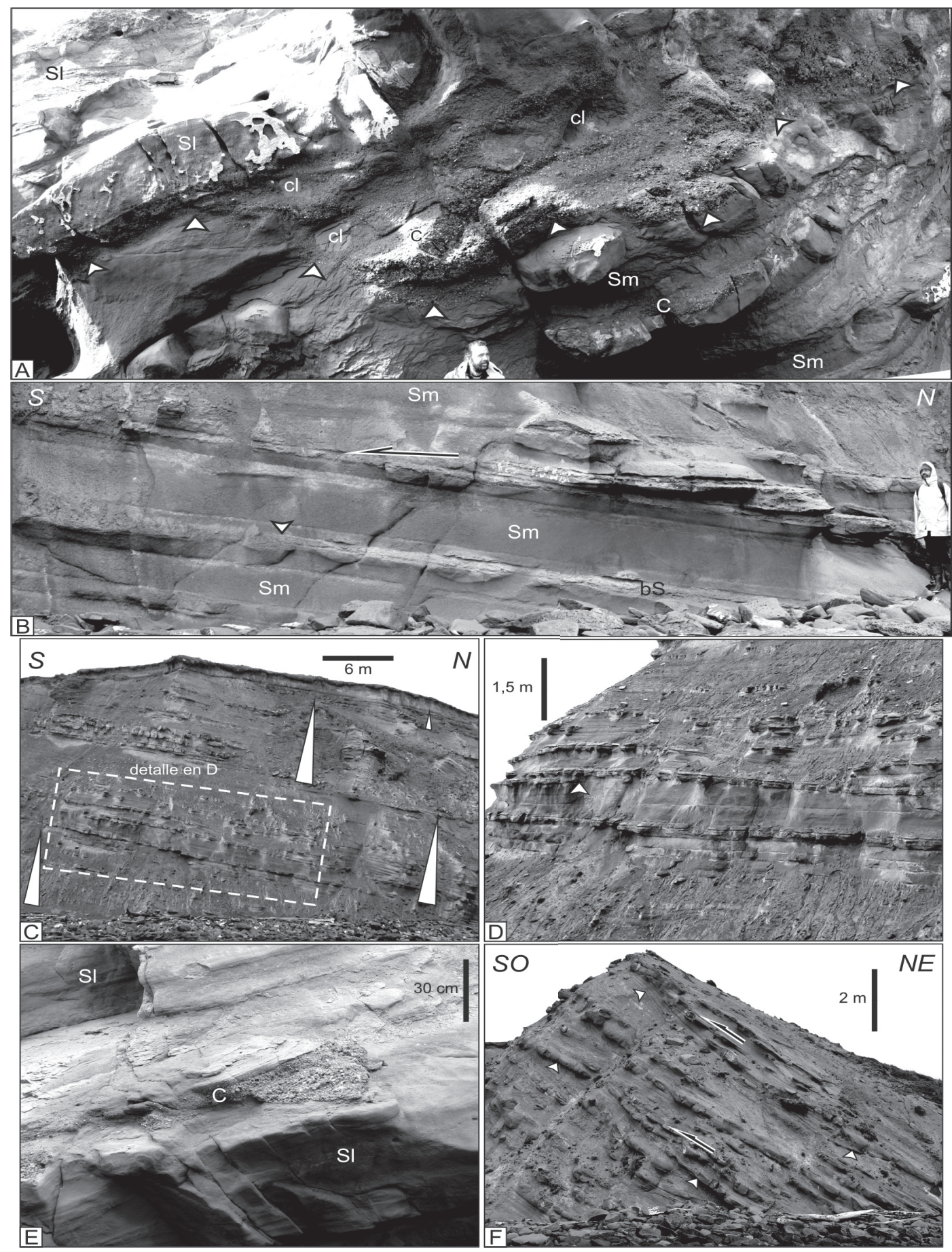

FIG. 17. Facies canalizadas reconocidas en la Formación Malengüena. A. Conglomerado (C) clasto sostén rellenando una superficie erosiva irregular (marcada por triángulos blancos) en una sucesión de arenisca maciza ( $\mathbf{S m}$ ) y con laminación (SI). Los clastos (cl) alcanzan tamaño de bloques; B. Superficies de acreción lateral (en el sentido de la flecha) en capas de arenisca maciza y con laminación difusa. El triángulo blanco indica la terminación lateral de una capa de arenisca bioturbada (bS); C-D. Sucesiones grano-estrato decrecientes con superficies de truncación erosiva (triángulo blanco en D); E. Lentes de conglomerado de base erosiva intercalados en bancos de arenisca con laminación paralela; F. Superficies de truncación erosiva (triángulos) cubiertas en relación de traslape (flechas) por bancos lenticulares de arenisca. 
relleno de ejes de canales, con gradación a facies más finas de desborde-albardón lateralmente y hacia el techo de los paquetes.

El Perfil Cabo Malengüena, de 123,5 m (Fig. 14), contiene paquetes de arreglo grano-estrato decreciente similares a los de la punta Isleta, de entre 45 y $15 \mathrm{~m}$ de espesor. En las bases de algunos paquetes los bancos en su conjunto forman geometrías sigmoidales perpendiculares a las direcciones de paleocorrientes, y se destacan además superficies de erosión internas (Fig. 17B, C, D). Las facies reconocidas incluyen conglomerado grueso a arenisca gruesa en bancos de $c a .1 \mathrm{~m}$ de espesor, maciza o con gradación normal y laminación paralela; y bancos delgados muy bioturbados de arenisca fina con laminación paralela, ondulitas de corriente y estructuras de deformación por carga (Fig. 16D). Se reconoce lateralmente a la secuencia del perfil en un afloramiento aislado por falla, un conglomerado matriz-sostén con clastos de hasta 0,3 m de diámetro, compuestos principalmente de sedimentitas (Fig. 16E). La composición petrográfica de las areniscas incluye feldespato, cuarzo y pizarras oscuras, volcanita, restos de concreciones y líticos sedimentarios (Fig. 16E, F). Además, contienen fragmentos de moluscos, corales y espinas de equinoideos.

A gran escala se reconocen en el Perfil Cabo Malengüena al menos cinco paquetes grano-estrato decrecientes con base erosiva y geometría lenticular, que varían en espesor lateralmente a lo largo del acantilado y la restinga, y constituyen el cuerpo principal del cabo (Fig. 13). Estos arreglos sumados a las geometrías sigmoidales generadas por acreción lateral (barras de punta), y las estructuras de corte y relleno internas, sustentan la interpretación de depósitos de canales equivalentes a los observados en la punta Isleta. Los paquetes canalizados superan los $20 \mathrm{~m}$ de potencia en la parte más espesa y alcanzan un mínimo de 500 a 800 m de extensión lateral (Fig. 13).

En el borde de la restinga de la punta Isleta, afloran solamente en las más bajas mareas niveles de arenisca fina en bancos delgados con estratificación entrecruzada, que se diferencian de la Formación Malengüena por su contenido en foraminíferos. Su descripción detallada no es posible debido al difícil acceso y muestreo de las areniscas. En este trabajo se limita a mencionarlos como'Estratos Innominados'. El contacto con la Formación Malengüena es neto, aparentemente discordante.
Límites y distribución. Lateralmente los afloramientos de la Formación Malengüena están limitados por el borde de la restinga en baja marea y por el borde superior del acantilado en el cabo Malengüena y la punta Isleta. Las capas de la formación son de rumbo variable debido a las geometrías de relleno de canal, promediando $\mathrm{N} 105^{\circ}$ con manteos al NE de $32^{\circ}$ a $22^{\circ}$ en la punta Isleta, y $\mathrm{N}^{\circ} 7^{\circ}$, con manteos de $23^{\circ}$ a $10^{\circ}$ al $\mathrm{NO}$ en el cabo Malengüena.

Numerosas fallas subverticales de rumbo N-S a NNE-SSO atraviesan ambos perfiles, produciendo desplazamientos menores a algunas decenas de metros en sentido horizontal, y de pocos metros en sentido vertical. En la playa que separa el cabo Malengüena de la punta Isleta se reconoce una zona de falla importante de orientación $\sim \mathrm{N} 50^{\circ}$ que produce un desplazamiento horizontal dextral de algunos cientos de metros entre ambos paquetes sedimentarios, dificultando la correlación de sus niveles (Falla Punta Isleta, Fig. 13).

Microfósiles. Los microfósiles de la Formación Malengüena comprenden foraminíferos en abundancia muy variable entre muestras, y espinas de equinodermos. No se hallaron ostrácodos, ni foraminíferos porcelanáceos, y los aglutinados son muy pocos e infrecuentes. Las conchillas calcáreas se preservan en casi su totalidad fragmentadas, con pérdida de la última cámara, y muchas de ellas vacías. Preservación similar no se ha reconocido en las demás formaciones cenozoicas de la Isla Grande de Tierra del Fuego.

En el Perfil Cabo Malengüena (Fig. 14), en las muestras 338, 338-1, 340, 371, 371-1 y 372, las especies dominantes Cibicides sp. y Globocassidulina cf. brocha sensu Cañón y Ernst en Natland et al. (1974) están acompañadas en forma muy subordinada por:

Angulogerina sp.; Anomalinoides alazanensis spissiformis (Cushman y Stainforth); Astrononion echolsi (Kennett); Cibicides temperatus (Vella); Cribrorotalia meridionalis (Cushman y Kellett); Eggerella sp.; Fissurina sp.; G. subglobosa; Guttulina sp.; Gyroidinoides soldanii (d'Orbigny); Martinottiella sp.; Polymorphina sp.

Las muestras MA71-1 a 71-3 del Perfil Cabo Malengüena contienen una típica asociación de Globocassidulina cf. brocha y Cibicides sp.; en particular las conchillas de la muestra MA71-3 están seleccionadas por tamaños menores, y esa 
muestra contiene glauconita, marcando la base de la Formación. La MA71-1 tiene un dominio absoluto de morfotipos epifaunales.

Se reconocieron además:

Alabamina ? sp.; Anomalinoides sp.; A. echolsi; Cribrorotalia sp.; Globocassidulina cf. cuneata (Finlay); Guttulina sp.; Gyroidinoides sp.; Heterolepa sp.; Lagenoglandulina sp.; Martinottiella sp.; N. longiscata; Polymorphina sp.; P. bulloides; Reticulophragmium sp.; S. bulloides; Stilostomella spp.; Uvigerina sp.

En el Perfil Punta Isleta Sur (Fig. 14), se diferencian las muestras 352 en donde el material está muy mal conservado y es muy escaso. Se destacan Vulvulina sp. y Cribrorotalia sp. La muestra 352-2 contrasta con las anteriores por sus abundantes foraminíferos planctónicos, de regular a mal conservados: Globigerina bulloides (d'Orbigny) entre formas de planctónicos indeterminables, y con abundante Globocassidulina $\mathrm{cf}$. brocha; y además contiene material retrabajado del Eoceno como 'K. 'severini.

En el Perfil Punta Isleta Norte (Fig. 14), las muestras 346 a 349-1 contienen muy pocos foraminíferos y mal preservados, extremadamente fragmentados. Se destacan las conchillas pardas y silicificadas provenientes del Cretácico Superior, de los géneros Glomospira y Haplophragmoides; y algunos polimorfínidos de gran tamaño, provenientes del Eoceno.

Tanto la composición taxonómica de la Formación Malengüena, dominada por Globocassidulina cf. brocha, como su peculiar preservación son características no reconocidas previamente en la porción argentina de la cuenca Austral.

Las muestras 350 y 351, que delimitan a los 'Estratos Innominados' (Fig. 14), se caracterizan por contener conchillas muy abundantes de foraminíferos planctónicos y escasos bentónicos, ambos muy mal preservados. Entre los primeros, debido a su muy pobre preservación, se distinguen abundantes formas espinosas como G. bulloides y formas asignables al género Sphaeroidinellopsis. Entre los bentónicos se reconocen sólo pocas formas ya representadas en los términos más bajos de la Formación Malengüena, y es también dominante Globocassidulina cf. brocha. La contrastante abundancia de foraminíferos planctónicos sugiere un pulso transgresivo marcado, y las determinacio- nes preliminares, una edad menor (posiblemente miocena media o pliocena) respecto a los términos estratigráficos subyacentes.

Edad. La aparición de S. bulloides para los Andes Fueguinos se reconoce a partir de la Formación Desdémona (Malumián y Olivero, 2006), de edad comprendida entre el Oligoceno más tardío y el Mioceno más temprano. Se define una edad máxima para la Formación Malengüena posterior al Chattiano temprano y posible miocena, pues Globocassidulina cf. brocha es un indicador del piso Gaviotiano (Natland et al., 1974), que es considerado del Mioceno.

Paleoambiente. Las facies de conglomerado clastosostén lenticulares reconocidas principalmente en la punta Isleta (Figs. 16A y 17A, E) sugieren depósitos residuales de flujos gravitatorios, probablemente asignables a las facies F3 de Mutti (1992). Las facies de conglomerado matriz-sostén (Fig. 16E) se interpretan como depósitos de flujos hiperconcentrados, mientras que los bancos tabulares de arenisca mediana a fina con estructuras de corriente tanto en el cabo Malengüena como en la punta Isleta (Figs. 16A, B, D y 17B) se atribuyen a depósitos de flujos concentrados y corrientes de turbidez (cf. Mulder y Alexander, 2001). En conjunto, constituyen una asociación de facies de depósitos de canales y albardones que se repite conformando un sistema retrogradante. Los canales fueron desarrollados probablemente sobre una superficie discordante de carácter regresivo, denotada por el pasaje desde facies de ambiente relativamente profundo del techo de la Formación Puesto José.

La Formación Malengüena corresponde a un ciclo de sedimentación con marcado control tectónico, producto de la erosión conjunta de las rocas que componen el orógeno Andino hacia el sur y de las secuencias anteriores de relleno de la cuenca de antepaís que son expuestas durante el desarrollo del corrimiento Malengüena (evidenciada por la abundancia de clastos de sedimentitas y foraminíferos del Cretácico y el Eoceno, Fig. 16E, F; Capítulo 6). Este ciclo marca la somerización y abandono de la subcuenca María Luisa en el sector de Península Mitre.

La confiabilidad de la interpretación paleoecológica, pese la fuerte caracterización de la composición taxonómica y tipo de preservación, es relativa dado que es función directa de la calidad de la preservación. La ausencia de miliólidos puede deberse a un ambiente desfavorable de vida y/o preservación diferencial respecto a la calcita magnesiana, 
ambos pueden ser resultado de la hiposalinidad; mientras que la escasez de aglutinados y las roturas de las conchillas de los foraminíferos calcáreos se deben a la energía del medio. La abundancia de Globocassidulina, un género infaunal posiblemente detritívoro, sugiere asociación a fango, aguas templadas a frías y a profundidades de plataforma a batiales (cf. Murray, 1991). Los escasos foraminíferos planctónicos en la mayoría de las muestras indican condiciones someras o desconexión con el mar abierto. Las muestras 350-351, en cambio, por su relación planctónicos a bentónicos y tamaño de los planctónicos, indican aguas de mayor profundidad que la plataforma, y la ausencia de especies filotérmicas junto con formas comparables indican aguas frías. Algunos de estos parámetros ecológicos son contradictorios y se interpretan como resultado de transporte postmortem de las conchillas, reflejado por las frecuentes roturas.

\section{Bioestratigrafía y Cronología}

En el intento de formalizar una biozonación cenozoica basada en foraminíferos para los Andes Fueguinos y extensible a la cuenca Austral, aplicable a la identificación y evaluación de sus discordancias y la cronología de los acontecimientos tectónicos (Olivero y Malumián, 1999; Malumián y Olivero, 2006; Malumián et al., 2008a), se reconoce una sucesión de datos bioestratigráficos. Estos datos corresponden mayormente a apariciones y desapariciones de especies de diferente confiabilidad que se deben ponderar dentro del marco de los dos mayores rasgos de la cuenca.

Uno es la posición extratropical de medianas altas latitudes de la cuenca Austral que, salvo en breves períodos, carece de las formas filotérmicas guías y de marcadores conocidos en las zonaciones tropicales-subtropicales. Esta carencia se acentúa acompañando el enfriamiento global de largo término del Cenozoico y la disminución de la diversidad en las altas latitudes, especialmente a partir del Oligoceno tardío. La baja resolución bioestratigráfica en Tierra del Fuego, desde las proximidades del límite Paleógeno-Neógeno hasta el Plioceno, se debe a la disminución de la diversidad -no se han reconocido géneros guías- y a que las pocas especies planctónicas remanentes son de prolongado biocrón.

Por otra parte, hay una marcada escasez de foraminíferos planctónicos que, en el Paleógeno temprano, se debe a una aparente desconexión con el mar abierto; y en el Paleógeno tardío-Neógeno temprano, a condiciones paleooceanográficas que habilitaron el acceso de aguas corrosivas responsables de la disolución de los micro y nanofósiles calcáreos. Estas condiciones llevan a considerar el dato local de la aparición de formas bentónicas resistentes a la disolución, el cual es de relativa confiabilidad dada la fuerte dependencia litofacial de la distribución de los foraminíferos bentónicos.

La resolución cronológica del Paleógeno de altas latitudes australes se ha beneficiado por la proposición de una zonación circumantártica de foraminíferos planctónicos (Huber y Quillévéré, 2005), que constituye una reciente referencia mayor por la calibración de los datos de aparición y desaparición de sus especies guías zonales. Sin embargo, algunos de ellos son inaplicables, como es el caso del dato de la desaparición de Chiloguembelina cubensis (Palmer) indicador del límite Oligoceno temprano-tardío, pues se trata de una especie sumamente infrecuente en Tierra del Fuego. Asimismo, la desaparición de 'Globigerina' euapertura (Jenkins), que señala el límite Oligoceno-Mioceno en la región circumantártica, es objetable debido a las escasas características morfológicas de esta especie y a su desaparición dependiente de la latitud, ya que para el sur de Australia alcanza el Mioceno temprano. De manera que de acuerdo con Spezzaferri (1994), el límite Oligoceno-Mioceno no es discernible mediante los foraminíferos planctónicos de altas latitudes.

La información adicional obtenida de la subcuenca María Luisa extiende y/o verifica algunos biocrones sumamente locales referidos a foraminíferos bentónicos. Se extiende el biocrón de la especie bentónica endémica ' $K$.' severini hasta la desaparición de la cosmopolita especie planctónica G. index. La extinción de la última se toma como una aproximación al límite Eoceno-Oligoceno, extrapolable a la extinción de la primera en los vastos ambientes de la cuenca Austral carentes de planctónicos. Queda también verificada la existencia de una discordancia dentro del entorno del límite Eoceno-Oligoceno.

Se corroboran, con posterioridad a la desaparición de $S$. angiporoides, las apariciones sucesivas de $S$. compressa y $S$. bulloides, que resultan ser homotaxiales en la cuenca Austral. Finalmente, es notoria la ausencia del género Transversigerina, de conchilla resistente a la disolución, de aparición 
previa y próxima al límite Oligoceno-Mioceno y de amplia distribución en la costa atlántica sudamericana hasta los $50^{\circ} \mathrm{S}$, aparentemente sin alcanzar las latitudes fueguinas.

\subsection{Discordancias cenozoicas}

Las discordancias se reconocen mediante la datación directa de los cuerpos de roca que las comprenden si se cuenta con la suficiente resolución bioestratigráfica en relación con la magnitud del hiato representado. Las discontinuidades de menor magnitud, dada la ubicuidad de los microfósiles, son fuertemente sugeridas por abruptas desapariciones y apariciones, las cuales comúnmente separan cuerpos de roca depositados en diferentes paleoambientes. Estos a su vez afectan posmortem las conchillas, dando como resultado diferentes preservaciones entre los cuerpos de roca separados por discordancias. Asimismo, los tramos estratigráficos estériles o de deficiente preservación están asociados a discordancias, generalmente por alteración de la roca subyacente a la discordancia y/o por estar más afectadas tectónicamente. Finalmente, el retrabajo de los microfósiles está asociado a discordancias, y la edad de los microfósiles retrabajados sugiere el origen del aporte sedimentario.

Si bien se han establecido las discordancias cenozoicas más extendidas en la cuenca Austral, sólo en pocos casos se ha testimoniado su cronología. El trabajo pionero que documentó sus edades en la cuenca Austral fue realizado en el histórico pozo estratigráfico SC-1 cuarenta años después de ser perforado, en donde se reconocieron las discordancias sobre el margen estable de la cuenca mediante foraminíferos y megafauna asociada, acompañándolo con las ilustraciones de los microfósiles determinados por primera vez en la Argentina (Malumián et al., 1971), complementados años después. Las mayores discordancias cenozoicas reconocidas en este pozo se situaron entre el Paleoceno (Daniano) y el Eoceno medio tardío, y entre este último y el 'Patagoniano'.

En el área de estudio se confirma la fuerte correspondencia entre las entidades estratigráficas diferenciadas anteriormente en el Paleógeno de Tierra del Fuego. Las asociaciones de foraminíferos bentónicos están fuertemente delimitadas en cada formación, e incluso en sus miembros, con abruptas desapariciones que reflejan relaciones discordantes. Además, sugieren discordancias en los casos en que no se conocen los contactos estratigráficamente normales.

A la fuerte diferenciación general de la composición taxonómica se suma la contrastante preservación revelada en los cuerpos de roca por una amplia variedad: desde conchillas excelentemente preservadas típicas de los ambientes deficitarios en oxígeno de la Formación La Barca hasta la ausencia total de conchillas calcáreas en los ambientes por debajo de la línea de compensación de la calcita. Asimismo, comprende preservaciones diferenciales por la solubilidad de las conchillas o tipo de carbonato, o con fuerte fragmentación de las conchillas de calcita, y ausencia de las conchillas de carbonato magnesiano como se destaca en la Formación Malengüena.

Además, en el área de estudio, el hallazgo de una asociación de foraminíferos calcáreos que contiene $S$. beccariiformis, en el miembro superior de la Formación La Barca, confirma la edad paleocena de este miembro, edad que se había asignado a toda la formación sólo por los microfósiles del miembro inferior (Olivero et al., 2002). Pese a que se trata de edades similares, la asociación de foraminíferos calcáreos del miembro superior difiere notablemente de la del miembro inferior (Malumián y Caramés, 2002), y es de una composición muy contrastante con la posterior Formación Punta Noguera. Mediante la verificación de la edad paleocena tardía del miembro superior de la Formación La Barca, el límite Paleoceno-Eoceno se sitúa entre las formaciones La Barca y Punta Noguera, cuyo contacto estratigráfico normal se desconoce. Considerando la contrastante diferencia entre sus microfaunas y preservaciones respectivas, el contacto se estima discordante.

Los estudios en progreso en Tierra del Fuego comprenden la búsqueda de especies diagnósticas en mayor cantidad y número de muestras en las localidades tipo de las formaciones reconocidas en el área de estudio, que mejoren la cronología de sus discontinuidades. La menor edad de la Formación Punta Noguera se acota en 53,39 Ma, por el hallazgo de $C$. wilcoxensis en su localidad tipo (comunicación oral, C. Náñez y G. Jannou, agosto de 2008), y se asigna al Ypresiano temprano. Además, se ha verificado la ausencia de Acarinina primitiva (Finlay) y acarinínidos en general en la base del miembro 'b' de la Formación Cerro Colorado, mediante la colección de más de 300 ejemplares de foraminíferos planctónicos, y aparentemente la ausencia 
alcanza hasta el miembro 'a' inclusive, indicando una edad menor a 39 Ma según estimaciones (Huber y Quillévéré, 2005).

Si se acepta la estimación de estos últimos autores del último registro de Planoglobulina australiformis (Jenkins) para altas latitudes, la Formación Río Bueno (Olivero et al., 2002) tendría una edad mayor a 46,70 Ma, asignable al Ypresiano tardíoLutetiano temprano precediendo a la Formación Leticia (43,70-39 Ma, Lutetiano tardío-Bartoniano temprano) al menos en $3 \mathrm{Ma}$.

\section{Estructura}

Las estructuras del área de estudio son el resultado de una compleja secuencia de corrimientos asociados a la evolución de la faja corrida y plegada Fueguina entre el Paleoceno más tardío y el ?Mioceno. Hacia el sur del área de estudio, en el cabo Leticia, se reconoce el anticlinal asimétrico homónimo (Olivero et al., 2002), de vergencia norte y rumbo subparalelo al par de pliegues desarrollados en la Formación La Barca al norte de la punta Ainol $\left(\mathrm{N} 100^{\circ}\right)$ (Figs. 2 y 3). Este anticlinal comprende en su núcleo a la Formación Cabo Leticia y en el limbo frontal presenta capas subverticales de las formaciones Cabo Leticia y La Barca, afectadas por fallas (Olivero et al., 2002). Las capas invertidas de la Formación Punta Noguera en la punta Ainol conforman el limbo frontal externo del anticlinal Cabo Leticia, que ha sido montado por el limbo frontal interno constituido por la Formación La Barca (Fig. 18). El corrimiento de bajo manteo asociado a esta estructura (Fig. 4A) es interpretado como el llano ('flat') superior del corrimiento Cabo Leticia, formador del anticlinal homónimo (Fig. 3). El desplazamiento asociado a dicho corrimiento produjo la fuerte rotación e inversión de las capas de la Formación Punta Noguera en el bloque yacente. De esta manera, el anticlinal Cabo Leticia corresponde a un pliegue por propagación de falla transportado, que en el bloque yacente produce un sinclinal de arrastre ('drag fold'). La mayor edad del anticlinal está acotada en el Ypresiano temprano, por la edad de la Formación Punta Noguera. El pulso tectónico responsable de la formación del anticlinal Cabo Leticia se denomina diastrofismo Cabo Leticia.

El par anticlinal-sinclinal en la Formación La Barca al norte de la punta Ainol está cubierto en discordancia angular por la Formación Leticia (Figs. 3 y 4), y por lo tanto su formación es anterior al Lutetiano tardío (43,70 Ma). Sobre la base de del paralelismo de esos pliegues con la estructura del anticlinal Cabo Leticia, que también afecta a la Formación La Barca, se asume que el par anticlinal-sinclinal mencionado se formó durante el diastrofismo Cabo Leticia. Este último marca la etapa inicial de un importante período de orogénesis en los Andes Fueguinos, que comenzó con la propagación del frente de deformación hacia el antepaís en el entorno del límite Paleoceno-Eoceno (cf. Ghiglione y Ramos, 2005; Torres Carbonell et al., 2008a, b). Este período de orogénesis regional tuvo como consecuencia la formación de la discordancia mayor entre el Paleoceno-Eoceno inferior y unidades más jóvenes en toda la cuenca, que en este trabajo denominamos P3 siguiendo a Galeazzi (1998). Como se mencionó antes, esta discordancia se reconoce en la base de la Formación Leticia en el sector norte de la punta Ainol. El desarrollo de la discordancia P3 implicó una importante erosión de las secuencias previas, lo que se manifiesta en el contacto tectónico entre las formaciones Punta Noguera y Leticia (Fig. 4C), y en el hiato implícito en el contacto entre esa última y la Formación La Barca.

El par de corrimientos que en la punta Ainol disponen a la Formación Leticia sobre la Formación Punta Noguera (retrocorrimiento M1 -M: Malengüena-), y a la Formación La Barca sobre la Formación Leticia (retrocorrimiento M2), tienen vergencia sur (Fig. 18). Dado que su vergencia es hacia el retropaís del orógeno Fueguino, se los considera retrocorrimientos. Estos retrocorrimientos son posteriores a la Formación Leticia, ya que desplazan en conjunto a los pliegues en la Formación La Barca cubiertos en discordancia por esa Formación.

Los retrocorrimientos M1 y M2 constituyen ramificaciones de un retrocorrimiento mayor que afecta la secuencia cenozoica despegando de niveles dentro o por debajo de la Formación La Barca. Este retrocorrimiento, denominado aquí Malengüena, también se identifica en el corte del río Malengüena en la sierra del mismo nombre (Fig. 2). El retrocorrimiento Malengüena desplazó una escama tectónica con manteo al norte constituida por las formaciones Leticia, Cerro Colorado y Puesto José entre la punta Ainol y la punta Isleta (Fig. 19).

La escama del retrocorrimiento Malengüena mantiene una orientación relativamente constante con rumbo aproximado E-O y manteos moderados en la parte sur de la escama y fuertemente inclinados en la parte norte $\left(50^{\circ} \mathrm{N}\right.$ en las capas de la Formación 
Puesto José hacia el sector del puesto La Chaira) (Fig. 19). Al norte de la bajada del puesto La Chaira, en la punta Isleta, se miden manteos de $34^{\circ}$ a $22^{\circ} \mathrm{N}$ en los niveles de la Formación Malengüena (Fig. 2). La Formación Cerro Colorado fue previamente interpretada como depósitos sintectónicos con desarrollo de estratos de crecimiento (Ghiglione y Ramos, 2005). Sin embargo, las estructuras mostradas por dichos autores como evidencia de discordancias sintectónicas son interpretadas aquí como parte de la arquitectura de los depósitos sedimentarios, que corresponden a canales con estratificación entrecruzada de gran escala (Fig. 8, cf. Fig. 10d de Ghiglione y Ramos, 2005). Canales similares son abundantes en el Mioceno subhorizontal de la cuenca Austral, sin relación con estructuras tectónicas activas (Ponce et al., 2008; Ponce y Olivero, 2008). El decrecimiento del ángulo de manteo hacia el norte entre la base $\left(50^{\circ} \mathrm{N}\right)$ y el techo $\left(30^{\circ} \mathrm{N}\right)$ de la Formación Cerro Colorado aumenta gradualmente a $40^{\circ} \mathrm{N}$ en la base de la Formación Puesto José, por lo que la disminución del manteo no es constante en toda la escama. Esta geometría se interpreta como producto de una flexura en el plano del retrocorrimiento Malengüena (Fig. 19), que ocasiona un menor manteo en parte de la escama tectónica. Cabe destacar que los escalones o flexuras de los corrimientos en fajas corridas y plegadas se encuentran documentadas en numerosos casos (ver Boyer y Elliot, 1982; McClay, 2004, entre otros), mientras que el decrecimiento del ángulo de manteo de una sucesión sedimentaria no es evidencia suficiente para definir estratos de crecimiento o discordancias progresivas, siendo para esto necesario una exposición más completa de la geometría de la estructura, donde se observen variaciones de espesor, acuñamiento de los estratos, y sobre todo una clara relación genética con la estructura de crecimiento asociada (Riba, 1976; Suppe et al., 1992).

La parte norte de la escama, cerca de su terminación, tiene manteos de $50^{\circ} \mathrm{N}$, muy por arriba de los valores moderados $\left(20^{\circ}\right.$ a $40^{\circ}$, por lo general cercanos a $30^{\circ}$ ) típicos de corrimientos en fajas corridas y plegadas (Boyer y Elliott, 1982; Suppe, 1985; Twiss y Moores, 2007, entre otros). En general, las secuencias de corrimientos de estilo 'piggy-back' dentro de una faja corrida y plegada implican que las primeras estructuras formadas sean incorporadas al bloque colgante ('hanging-wall') de las posteriores, lo que resulta en rotación de las estructuras más viejas (Mitra, 1986; Butler, 1987).
Por lo tanto, se propone que el manteo de $50^{\circ}$ en la parte norte de la escama del retrocorrimiento Malengüena fue adquirido por rotación, debida a una etapa tectónica posterior.

Las edades del retrocorrimiento Malengüena y de su posterior rotación están acotadas entre la edad de los niveles de plegamiento sinsedimentario de la sección superior de la Formación Puesto José (Oligoceno 'medio', mayor a $30 \mathrm{Ma}$ ), y la edad de la discordancia en la base de la Formación Malengüena (?Mioceno). Los niveles de plegamiento sinsedimentario en el perfil tipo de la Formación Puesto José, que superan los $50 \mathrm{~m}$ de espesor estratigráfico, son interpretados como depósitos sintectónicos que manifiestan la deformación activa durante la formación de la lámina del retrocorrimiento en posiciones internas de la cuenca. Esto se sustenta en la notable tendencia grano-estrato creciente por encima de estos niveles, que contrasta con las facies de fangolitas y turbiditas finas subyacentes, y que indica progradación en el sistema atribuible a control tectónico. De esta manera, la edad máxima del retrocorrimiento Malengüena estaría comprendida en el Rupeliano tardío, acotada por la presencia de $S$. angiporoides (última aparición calibrada en $30 \mathrm{Ma}$ ) en las capas del techo de la Formación Puesto José cerca de la bajada del puesto La Chaira.

La discordancia en la base de la Formación Malengüena, por otro lado, involucra un hiato temporal mínimo que comprende a todo el Oligoceno tardío (ca. $5 \mathrm{Ma}$ ) en el sector de la bajada del puesto La Chaira. El hiato implica la erosión de las capas de la Formación Puesto José posteriores a la última aparición de $S$. angiporoides (Chattiano), expuestas en el perfil del cabo Malengüena (230 m de espesor; Fig. 11). La extensión lateral de esta superficie de erosión entre el cabo Malengüena y la punta Isleta no se puede precisar debido al desplazamiento producido por el sistema de fallas Punta Isleta, pero se estima que superaría los $5 \mathrm{~km}$.

La erosión del Chattiano durante el desarrollo de la discordancia acota al Mioceno la mayor edad del plegamiento de la Formación Malengüena, que coincidió con la rotación postulada para el retrocorrimiento Malengüena. Estudios en curso por parte de los autores atribuyen el desarrollo de la discordancia y esta última etapa de deformación, a la formación de estructuras profundas vinculadas a la faja corrida y plegada (Torres Carbonell et al., 2008b, Fig. 19). 


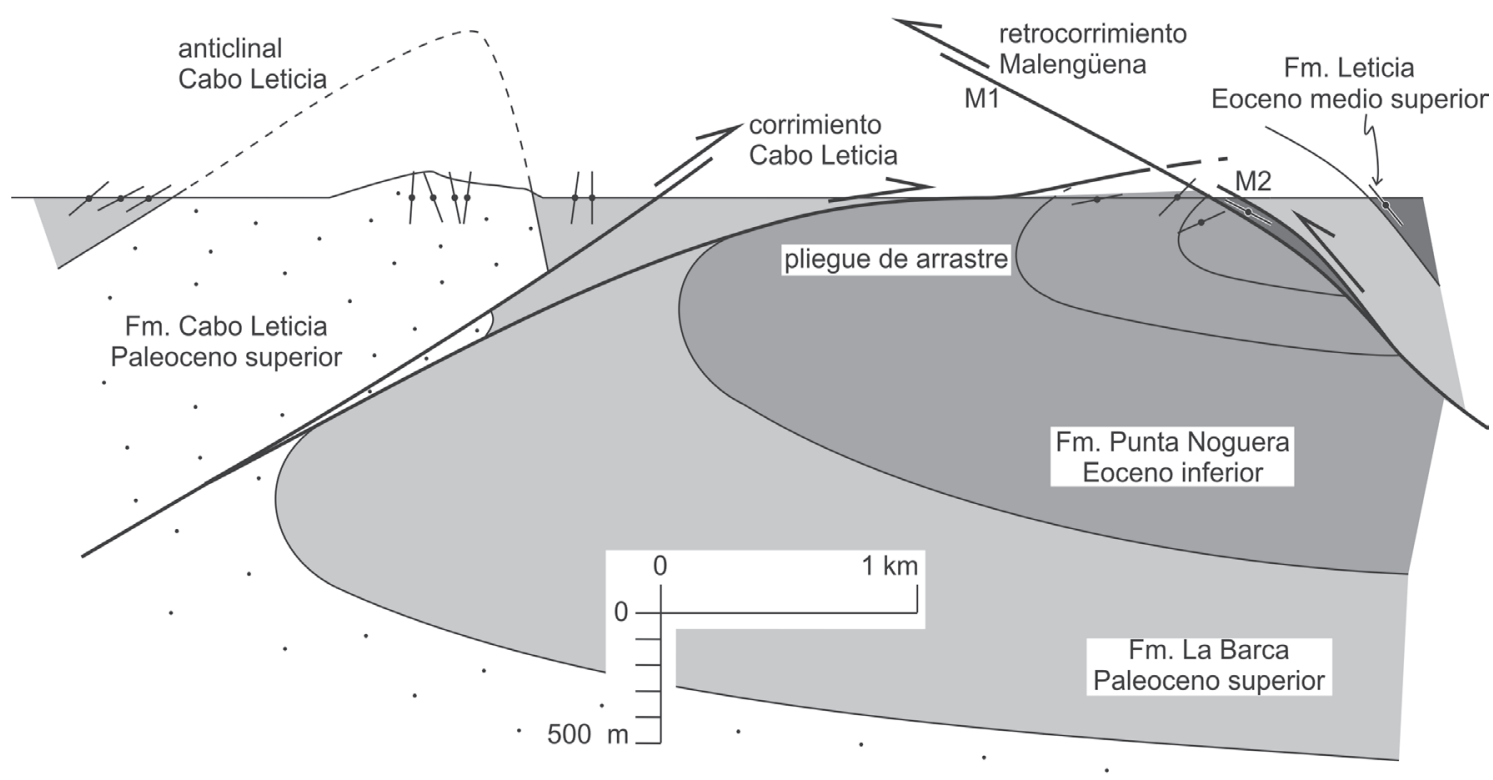

FIG. 18. Sección estructural entre el cabo Leticia y la punta Ainol. Ver mapas complementarios en las figuras 2 y 3.

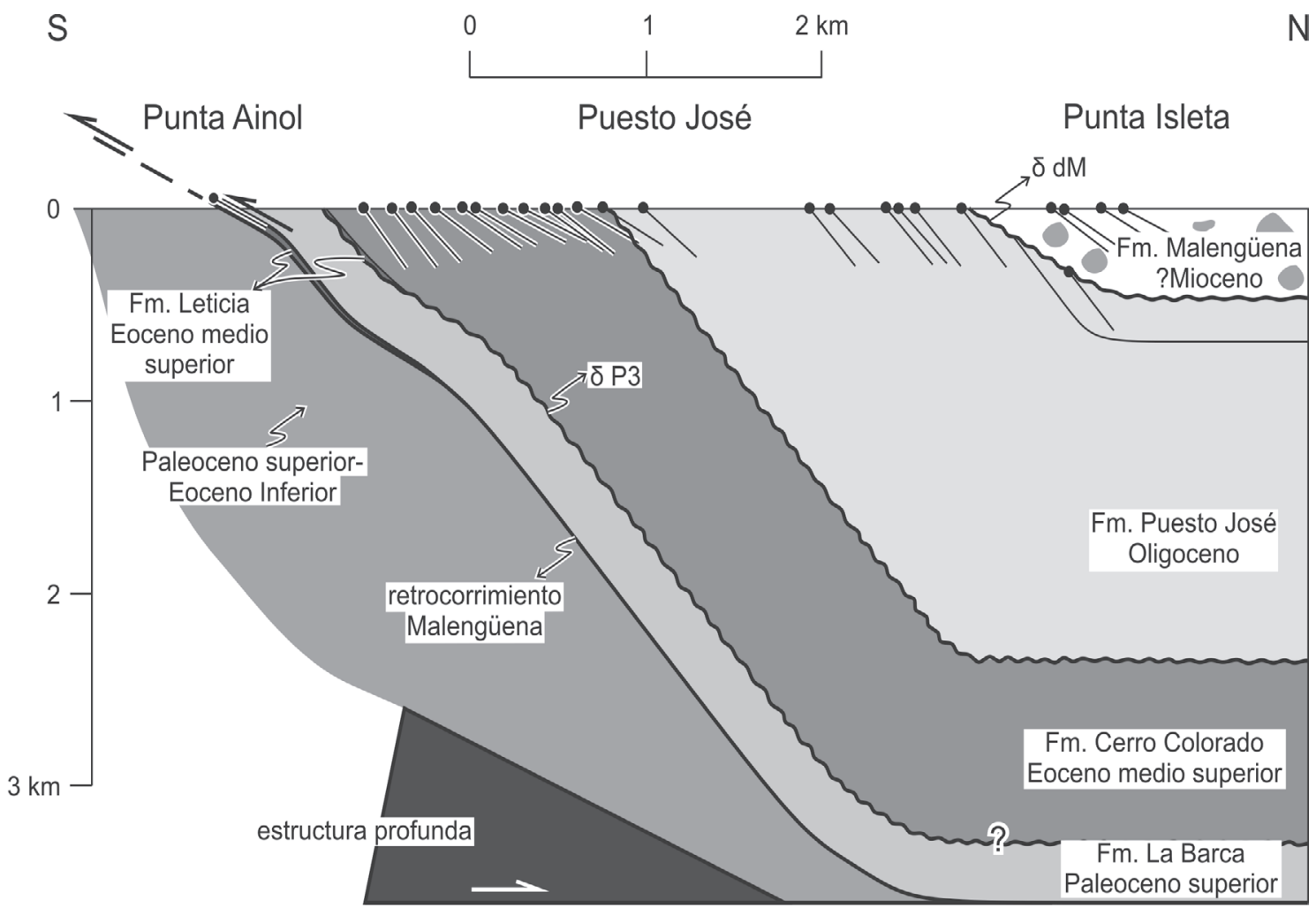

FIG. 19. Sección estructural entre la punta Ainol y la punta Isleta. dM: discordancia Malengüena. Ver ubicación en la figura 2. 


\section{Evolución de la subcuenca María Luisa}

La etapa orogénica regional que tuvo lugar en el extremo sur de América del Sur entre el límite Paleoceno-Eoceno y el Eoceno medio fue producto de un cambio en la dirección y velocidades de convergencia de las placas tectónicas del Pacífico sudeste, y causó intensa deformación en los Andes Fueguinos y Patagónicos australes (Candie y Leslie, 1986; Klepeis, 1994; Kohn et al., 1995; Ramos, 2005). En el sector de la costa Atlántica Fueguina, la etapa de intensa deformación comenzó con la propagación hacia el antepaís del frente de la faja corrida y plegada, desarrollando estructuras compresivas que afectaron la antefosa Paleocena tardía-Eocena temprana (Torres Carbonell et al., 2008a, b). La actividad tectónica progresó hasta el Eoceno medio y favoreció el desarrollo de la discordancia regional $\mathrm{P}$, identificada con variada expresión en las cuencas Austral y Malvinas entre la antefosa paleocena-eocena temprana y el Eoceno medio tardío (Malumián et al., 1971; Biddle et al., 1986; Galeazzi, 1998; Malumián y Olivero, 2006; Torres Carbonell et al., 2008a; Fig. 10). En el área de estudio, la superficie P3 se reconoce entre las formaciones La Barca (Paleoceno superior) y Leticia (43,70-39 Ma), indicando, por lo tanto, un hiato temporal mínimo de $12 \mathrm{Ma}$ (Fig. 10).

La propagación del frente de deformación de la faja corrida y plegada en el Eoceno inferior ocasionó una segmentación dentro del sistema deposicional de la cuenca de antepaís. La generación durante este pulso compresivo de un anticlinal en el extremo norte del despegue basal de la faja corrida y plegada, desconectó parcialmente de la antefosa al depocentro de techo de cuña, la subcuenca María Luisa, formado hacia el sur (Torres Carbonell et al., 2008a). La subcuenca María Luisa alberga un relleno sedimentario que cubrió la superficie erosiva P3 desarrollada sobre las estructuras previas, entre el frente orogénico activo hasta el Paleoceno tardío y el posterior frente formado entre el Eoceno inferior y medio.

De acuerdo con las exposiciones en el área de estudio, el relleno de la cuenca comenzó durante el Eoceno medio tardío con los depósitos de la Formación Leticia, que cubrieron la superficie de erosión producida sobre la Formación La Barca, y son correlativos con una transgresión generalizada en toda la cuenca Austral (Malumián, 1999). La depositación ocurrió en ambientes de nivel del mar relativamente bajo durante la etapa inicial de subsidencia posterior al período orogénico del Eoceno temprano a medio. Los depósitos de la Formación Cerro Colorado, en particular los de la sección inferior, se acumularon a continuación durante una etapa de profundización relativa respecto de los ambientes de la Formación Leticia, aunque en condiciones de desconexión con la circulación de aguas en mar abierto.

Durante fines del Eoceno y principios del Oligoceno, un nuevo pulso de deformación en la faja corrida y plegada favoreció el desarrollo de una discordancia labrada en las sucesiones de la cuenca de antepaís. Esta discordancia se reconoce particularmente en los depósitos de la cuenca María Luisa y en la antefosa adyacente al frente de la faja corrida y plegada, y se corresponde con la base del Conglomerado Tchat-Chii que tiene variada expresión en la cuenca (Malumián y Olivero, 2006). En el caso de la subcuenca María Luisa, la discordancia está relacionada localmente con la actividad del retrocorrimiento Campo del Medio, que genera el anticlinal del mismo nombre (Torres Carbonell et al., 2008a; Fig. 20).

En el sector de estudio, la discordancia se identifica en el contacto de las formaciones Cerro Colorado y Puesto José, por encima de la primera aparición local de $C$. dissimilis y de niveles con Ch. otorara (Oligoceno basal). La aparente discordancia reconocida en niveles de la muestra 168 de la Formación Cerro Colorado (nivel $750 \mathrm{~m}$ del Perfil SE) (Fig. 7) puede estar relacionada con el origen de la discordancia mayor (Fig. 10). El techo de la Formación Cerro Colorado contiene la mayor proporción de foraminíferos planctónicos del perfil, por lo que se infiere un nivel del mar en aumento o una menor restricción de la subcuenca durante el entorno del límite Eoceno-Oligoceno. Esta inferencia es consistente con los depósitos marinos profundos del Oligoceno temprano de la cuenca Austral (Malumián y Olivero, 2006; Scarpa y Malumián, 2008). En el caso de estudio, la profundización del ambiente podría estar relacionada con una creciente subsidencia flexural, vinculada a orogénesis durante el límite EocenoOligoceno (cf. Flemings y Jordan, 1990).

El relleno de la subcuenca María Luisa durante el Oligoceno continuó con los depósitos de talud deposicional de la Formación Puesto José (Fig. 20A). El importante espesor de esta Formación (ca. $1.600 \mathrm{~m}$ ), en contraste con menores espesores en los sectores marginales de la subcuenca y en el borde meridional de la antefosa (capas de la Estancia 
A

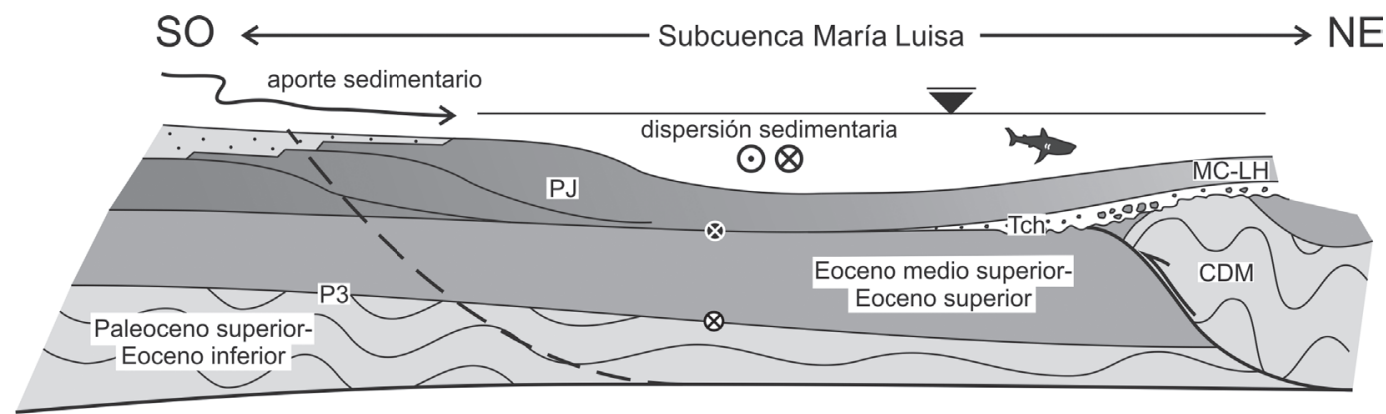

B

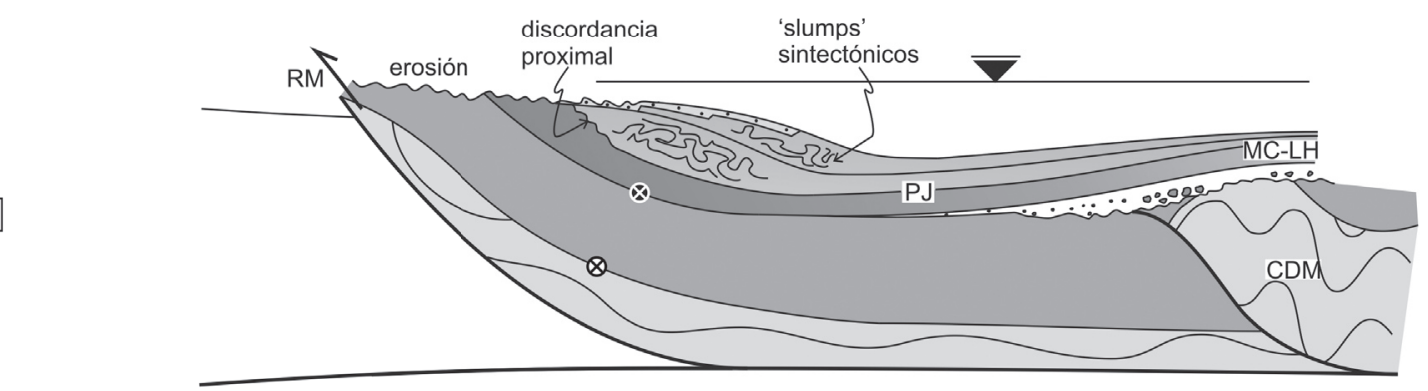

C
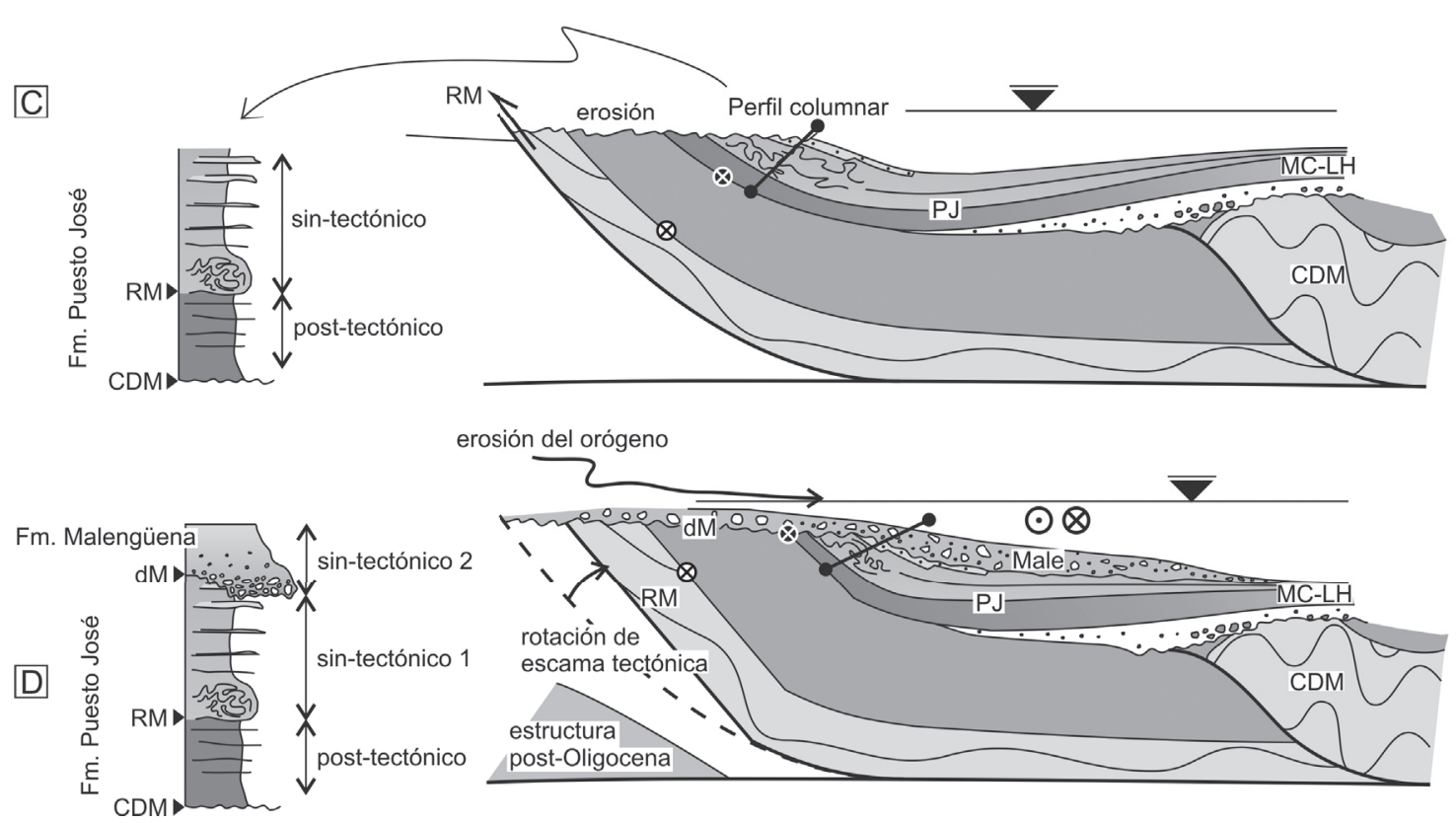

FIG. 20. Evolución de la subcuenca de techo de cuña María Luisa entre el Oligoceno y el Mioceno. Ver explicación en el texto. CDM. anticlinal Campo del Medio; Tch: Conglomerado Tchat-chii (Oligoceno basal); PJ: Formación Puesto José (Oligoceno); MC-LH: capas de la Estancia María Cristina y del Puesto Herminita (Oligoceno); RM: retrocorrimiento Malengüena; dM: discordancia Malengüena; Male: Formación Malengüena (Mioceno). Las marcas con cruces indican el desplazamiento de la escama tectónica. Se indica esquemáticamente la dispersión sedimentaria transversal (flecha sinuosa) y paralela (círculos) al eje del depocentro.

María Cristina y del Puesto Herminita; Malumián y Olivero, 2006; Fig. 10), evidencia el control tectónico en la localización de los depocentros afectados por subsidencia flexural. Se infiere que durante el Oligoceno, la actividad tectónica en el margen septentrional de la subcuenca María Luisa (anticlinal 
Campo del Medio) condicionó los espesores allí acumulados (Fig. 20).

Luego del desarrollo del retrocorrimiento Campo del Medio y de la depositación de la parte inferior de la Formación Puesto José (postectónico, Fig. 20C), una nueva etapa tectónica hacia el Oligoceno 'medio' produjo la formación del retrocorrimiento Malengüena, que afectó al relleno sedimentario de la cuenca María Luisa en el área de estudio. La sección superior de la Formación Puesto José, que expone pliegues sinsedimentarios de gran extensión hacia la base y una sucesión turbidítica progradante al techo, corresponde al relleno sintectónico de la subcuenca durante la actividad del retrocorrimiento Malengüena (sintectónico 1, Fig. 20C), que culmina con el levantamiento y erosión de parte de la sucesión (Fig. 20B, C).

Finalmente, luego del Oligoceno tardío la reactivación de estructuras profundas de la faja corrida y plegada en el sector de análisis produjo deformación de estructuras previas, y la generación de una cuña clástica probablemente sintectónica correspondiente a los depósitos de la Formación Malengüena (sintectónico 2, Fig. 20D). Se estima que dichos depósitos son miocenos, producto de la erosión de la Cordillera Fueguina y de la escama del retrocorrimiento Malengüena. La discordancia en la base de la Formación Malengüena involucra un hiato de aproximadamente $5 \mathrm{Ma}$, y se denomina para referencia discordancia Malengüena $(\mathrm{dM})$ (Figs. 19 y 20). Esta discordancia marca el último pulso de deformación compresiva en el sector de estudio, que implicó el aborto de la mayor parte de la subcuenca María Luisa, ocasionado posiblemente por el retroceso de la línea de costa y el comienzo de erosión subaérea en el área del depocentro.

\section{Conclusiones}

La columna sedimentaria del Paleoceno superior?Mioceno expuesta en la costa norte de Península Mitre, entre la punta Ainol y el cabo Malengüena, se compone de sucesiones limitadas por discordancias de diversa magnitud, y se divide en dos grandes conjuntos separados por una discordancia mayor, reconocida históricamente en toda la cuenca: el Paleoceno superior-Eoceno inferior $(550 \mathrm{~m})$ y el Eoceno medio superior-?Mioceno $(>2.900 \mathrm{~m})$. La columna se subdivide en las formaciones La Barca (Paleoceno superior), Punta Noguera (Eoceno inferior), Leticia (Eoceno medio superior), Cerro
Colorado (Eoceno medio superior-Eoceno superior), y Puesto José (nom. nov., Oligoceno), identificables y/o correlacionables con las sedimentitas aflorantes en Tierra del Fuego y con las entidades estratigráficas de subsuelo, y la Formación Malengüena (nom. nov., ?Mioceno), que contiene una asociación de foraminíferos fuertemente distinguible por su composición taxonómica dominada por Globocassidulina cf. brocha, y por su peculiar preservación, ambas características no reconocidas previamente en la porción argentina de la cuenca Austral. Las formaciones La Barca y Punta Noguera se depositaron en la antefosa paleocena tardía-eocena temprana de la cuenca Austral-Malvinas, mientras que la sucesión del Eoceno medio superior-?Mioceno se identifica como el relleno de la subcuenca María Luisa, depocentro de techo de cuña del sistema de cuenca de antepaís.

Las discordancias identificadas se vinculan a la evolución de la faja corrida y plegada Fueguina. La discordancia en la base del Eoceno medio superior corresponde a un período de orogénesis en los Andes Fueguinos, y marca el cambio de la antefosa al dominio del depocentro de techo de cuña en el margen orogénico de la cuenca Austral. La discordancia en el entorno del límite Eoceno-Oligoceno se relaciona con una etapa de deformación reconocida también en el margen norte de la subcuenca María Luisa. La deformación sinsedimentaria en el tramo superior de la Formación Puesto José se vincula al desarrollo del retrocorrimiento Malengüena, que produce levantamiento y erosión de parte de la secuencia de la subcuenca durante el Oligoceno 'medio'. Una última etapa diastrófica produce deformación y exhumación de la subcuenca, junto con el desarrollo de la discordancia erosiva en la base de la Formación Malengüena durante el ?Mioceno.

Se extienden y/o verifican biocrones locales de foraminíferos bentónicos: la extinción de ' $K$.' severini se aproxima a la desaparición de $G$. index, indicadora del límite Eoceno-Oligoceno; y la desaparición de $S$. angiporoides es seguida por la sucesiva aparición de $S$. compressa y $S$. bulloides. Además, se confirma la edad paleocena tardía de la Formación La Barca, y se sitúa al límite PaleocenoEoceno entre ésta y la Formación Punta Noguera; y se confirma una edad menor a 39 Ma para la base de la Formación Cerro Colorado, verificando la ausencia de acarínidos. 
La integración de una sucesión sedimentaria biozonada de $c a .2 .900 \mathrm{~m}$ al dominio de techo de cuña del sistema de cuenca de antepaís AustralMalvinas, constituye un aporte novedoso y de suma relevancia para los modelos de exploración petrolera. En particular, la descripción de grandes espesores intercalados de pelitas y areniscas asociados a estructuras de la faja corrida y plegada, en conjunción con información de subsuelo, es un objetivo de interés en la evaluación de trampas estratigráficas y estructurales.

\section{Agradecimientos}

Se agradece a A. Sobral (CADIC-CONICET) por la colaboración en trabajos de campo y realización de cortes petrográficos; a los propietarios de la Estancia Policarpo por permitir el acceso al terreno, y en particular la hospitalidad de N. Oyarzún y N. Ainol $(\dagger)$ del puesto La Chaira, y a J. Contreras. Este trabajo se dedica a la memoria de N. Ainol, hombre de campo y poblador de Península Mitre, fallecido en agosto de 2007. Se agradece a T. Hromic (Instituto de la Patagonia, Chile), J. Le Roux (Universidad de Chile), J. Vergés (Institut de Ciencies de la Terra Jaume Almera, España) y V. Ramos (Universidad de Buenos Aires-CONICET, Argentina) por la revisión del manuscrito. El Proyecto Consolidar CGL2007-63724/ BTE del Ministerio de Educación y Ciencia de España brindó apoyo bibliográfico. El financiamiento se obtuvo del PIP 5100 (CONICET) y del PICTO 36315 (FONCYT) a cargo de E.B.O.

\section{Referencias}

Allen, P.A.; Allen, J.R. 1990. Basin analysis, principles and applications. Blackwell Scientific Publications: 451 p. London.

Berggren, W.A.; Kent, D.V.; Swisher III, C.C.; Aubry, M.-P. 1995. A revised Cenozoic geochronology and chronostratigraphy. Society for Sedimentary Geology Special Publication 54: 129-212.

Biddle, K.T.; Uliana, M.A.; Mitchum, Jr., R.M.; Fitzgerald, M.G.; Wright, R.C. 1986. The stratigraphic and structural evolution of the central and eastern Magallanes basin, southern South America. In Foreland Basins (Allen, P.A.; Homewood, P.; editors). International Association of Sedimentologists Special Publication 8: 41-61.

Boyer, S.E.; Elliott, D. 1982. Thrust systems. American Association of Petroleum Geologists, Bulletin 66: 1196-1230.

Butler, R.W.H. 1987. Thrust sequences. Journal of the Geological Society of London 144: 619-634.

Candie, S.C.; Leslie, R.B. 1986. Late Cenozoic tectonics of the southern Chile trench. Journal of Geophysical Research 91: 471-496.

Caramés, A.; Malumián, N. 2006. La Familia Rzehakini- dae (Foraminifera) en el Cretácico Superior-Paleógeno de la cuenca Austral y la plataforma continental atlántica adyacente, Argentina. Ameghiniana 43: 649-668.

Criado Roque, P.; de Ferrariis, C.; Mingramm, A.; Rolleri, E.O.; Simonato, I.B.; Suero, T. 1959. Cuencas sedimentarias de la Argentina. Boletín de Informaciones Petroleras 320: 816-834.

Dalziel, I.W.D.; de Wit, M.J.; Palmer, K.F. 1974. Fossil marginal basin in the southern Andes. Nature 250: 291-294.

Dalziel, I.W.D.; Storey, B.C.; Garrett, S.W.; Grunow, A.M.; Herrod, L.D.B.; Pankhurst, R.J. 1987. Extensional tectonics and the fragmentation of Gondwanaland. In Continental extensional tectonics (Coward, M.P.; Dewey, J.F.; Hancock, P.L.; editors). Geological Society of London, Special Publication 28: 433-441. London.

DeCelles, P.G.; Giles, K.A. 1996. Foreland basin systems. Basin Research 8: 105-123.

De Ferrariis, C. 1938. En Fossa Mancini, E.; Feruglio, E.; Yussen de Campana, J.C. Una reunión de geólogos de YPF y el problema de la terminología estratigráfica. Boletín de Informaciones Petroleras 165: 44-45, 94-95.

Dott, Jr., R.H.; Winn, Jr., R.D.; Smith, C.H.L. 1982. Relationship of late Mesozoic and early Cenozoic sedimentation to the tectonic evolution of the Southernmost Andes and Scotia Arc. In Antarctic Geoscience (Craddock, C.; editor). University of Wisconsin Press: 193-202. Madison.

Flemings, P.B.; Jordan, T.E. 1990. Stratigraphic modeling of foreland basins: interpreting thrust deformation and lithosphere rheology. Geology 18: 430-434.

Furque, G.; Camacho, H.H. 1949. El Cretácico Superior de la costa Atlántica de Tierra del Fuego. Revista de la Asociación Geológica Argentina 4: 263-297.

Galeazzi, J.S. 1998. Structural and stratigraphic evolution of the western Malvinas basin, Argentina. American Association of Petroleum Geologists Bulletin 82: 596-636.

Ghiglione, M.C. 2003. Estructura y evolución tectónica del Cretácico-Terciario de la costa Atlántica de Tierra del Fuego. Tesis Doctoral (Inédito), Universidad de Buenos Aires, Facultad de Ciencias Exactas y Naturales: $150 \mathrm{p}$.

Ghiglione, M.C.; Ramos, V.A. 2005. Progression of deformation and sedimentation in the southernmost Andes. Tectonophysics 405: 25-46.

Hornibrook, N. de B.; Brazier, R.C.; Strong, C.P. 1989. Manual of New Zealand Permian to Pleistocene Foraminiferal Biostratigraphy. New Zealand Geological Survey, Paleontological Bulletin 56: 1-175.

Huber, B.T.; Quillévéré, F. 2005. Revised Paleogene planktonic foraminiferal biozonation for the Austral Realm. Journal of Foraminiferal Research 35: 299314 .

Jannou, G. 2007. Radiolarios del Paleógeno de cuenca 
Austral, Tierra del Fuego. Argentina. Ameghiniana 44: 447-466.

Klepeis, K.A. 1994. Relationship between uplift of the metamorphic core of the southernmost Andes and shortening in the Magallanes foreland fold and thrust belt, Tierra del Fuego, Chile. Tectonics 13: 882-904.

Kohn, M.J.; Spear, F.S.; Harrison, T.M.; Dalziel, I.W.D. 1995. $\mathrm{Ar}^{40} / \mathrm{Ar}^{39}$ geochronology and P-T-t paths from the Cordillera Darwin metamorphic complex, Tierra del Fuego, Chile. Journal of Metamorphic Geology 13: 251-270.

Malumián, N. 1988. Foraminíferos bentónicos de la localidad tipo de la Formación La Despedida (Eoceno, Isla Grande de Tierra del Fuego). Parte I. Textulariina y Miliolina. Ameghiniana 25: 341-356.

Malumián, N. 1999. La sedimentación y el volcanismo terciario en la Patagonia Extraandina: La sedimentación en la Patagonia Extraandina. In Geología Argentina (Caminos, R.; editor). Anales 29 (18): 557-612. Buenos Aires.

Malumián, N.; Caramés, C. 2002. Foraminíferos de sedimentitas ricas en carbono orgánico: Formación La Barca, Paleoceno superior, Tierra del Fuego, República Argentina. Revista de la Asociación Geológica Argentina 57: 219-231.

Malumián, N.; Olivero, E.B. 2005. Shallow-water late middle Eocene crinoids from Tierra del Fuego: a new southern record of a retrograde community structure. In The Magellan Antarctic connection: links and frontiers at high southern latitudes (Arntz, W.E.; Lovrich, G.A.; Thatje, S.; editors). Scientia Marina 69, Supplement 2: 349-353.

Malumián, N.; Olivero, E.B. 2006. El Grupo Cabo Domingo, Tierra del Fuego, Argentina: Bioestratigrafía, paleoambientes y acontecimientos del Eoceno-Mioceno marino. Revista de la Asociación Geológica Argentina 61: 139-160.

Malumián, N.; Olivero, E.B. (2008). Biostratigraphy of the Campanian-Lower middle Eocene: Fueguian Andes. In Congreso Geológico Argentino, No. 17. Resúmenes: 855. Jujuy.

Malumián, N.; Masiuk, V.; Riggi, J.C. 1971. Micropaleontología y sedimentología de la perforación SC-1, Provincia de Santa Cruz, República Argentina. Su importancia y correlaciones. Revista de la Asociación Geológica Argentina 26: 175-208.

Malumián, N.; Olivero, E.B.; Náñez, C. 2008a. Bioestratigrafía del Eoceno medio superior-Mioceno de los Andes Fueguinos. In Congreso Geológico Argentino, No. 17, Resúmenes: 856, 863. Jujuy.

Malumián, N.; Náñez, C.; Alonso, M.S.; Baleirón, A. 2008b. Pozo Poseidón 1: El Paleógeno de la plataforma continental, Isla Grande de Tierra del Fuego. In Congreso Geológico Argentino, No. 17. Resúmenes: 859-860. Jujuy.

Masiuk, V.; Riggi, J.C.; Bianchi, J.L. 1990a. Análisis geológico del Terciario del subsuelo de Tierra del Fuego (Parte I). Boletín de Informaciones Petroleras 21: 70-89.

Masiuk, V.; Riggi, J.C.; Bianchi, J.L. 1990b. Análisis geológico del Terciario del subsuelo de Tierra del Fuego (Parte II). Boletín de Informaciones Petroleras 22: 8-26.

McClay, K.R. 2004. Thrust tectonics and hydrocarbon systems. American Association of Petroleum Geologists, Memoir 82: 667 p. Tulsa.

Mitra, S. 1986. Duplex structures and imbricate thrust systems: geometry, structural position, and hydrocarbon potential. American Association of Petroleum Geologists, Bulletin 70: 1087-1112.

Mulder, T.; Alexander, J. 2001. The physical character of subaqueous sedimentary density flows and their deposits. Sedimentology 48: 269-299.

Murray, J.W. 1991. Ecology and palaeoecology of benthic foraminifera. Longman Scientific and Technical: 397 p. New York.

Mutti, E. 1992. Turbidite sandstones. AGIP-Instituto di Geologia, Università di Parma: 275 p. San Donato Milanese.

Mutti, E.; Tinterri, R.; Remacha, E.; Mavilla, N.; Angella, S.; Fava, L. 1999. An introduction to the analysis of ancient turbidite basins from an outcrop perspective. American Association of Petroleum Geologists, Continuing Education Course Note Series 39: 93 p. Tulsa.

Mutti, E.; Tinterri, R.; di Biase, D.; Cavana, G. 2003. Deltaic, mixed and turbidite sedimentation of ancient foreland basins. Marine and Petroleum Geology 20: 733-755.

Natland, M.L.; González, E.; Cañón, A.; Ernst, M. 1974. A system of stages for correlation of Magallanes Basin sediments. Geological Society of America, Memoir 139: 1-126.

Olivero, E.B. 2002. Petrografía sedimentaria de sistemas turbidíticos del Cretácico-Paleógeno, Andes Fueguinos: Procedencia, volcanismo y deformación. In Congreso Geológico Argentino, No. 15, Actas. CD-ROM, artículo 15. El Calafate.

Olivero, E.B.; Malumián, N. 1999. Eocene stratigraphy of southeastern Tierra del Fuego island, Argentina. American Association of Petroleum Geologists, Bulletin 83: 295-313.

Olivero, E.B.; Malumián, N. 2002. Upper CretaceousCenozoic clastic wedges from the Austral-Malvinas foreland basins, Tierra del Fuego, Argentina: eustatic and tectonic controls. In European Meeting on the Paleontology and Stratigraphy of Latin America III. Addendum: 6-9. Toulouse.

Olivero, E.B.; Malumián, N. 2008. Mesozoic-Cenozoic stratigraphy of the Fuegian Andes, Argentina. Geologica Acta 6 (1): 5-18.

Olivero, E.B.; Martinioni, D.R. 1996. Late Albian inoceramid bivalves from the Andes of Tierra del 
Fuego. Age implications for the closure of the Cretaceous marginal basin. Journal of Paleontology 70: 272-274.

Olivero, E.B.; Malumián, N.; Palamarczuk, S.; Scasso, R.A. 2002. El Cretácico Superior-Paleógeno del área del Río Bueno, costa atlántica de la Isla Grande de Tierra del Fuego. Revista de la Asociación Geológica Argentina 57: 199-218.

Olivero, E.B.; Malumián, N.; Palamarczuk, S. 2003. Estratigrafía del Cretácico Superior-Paleoceno del área de bahía Thetis, Andes Fueguinos, Argentina: acontecimientos tectónicos y paleobiológicos. Revista Geológica de Chile 30 (2): 245-263.

Olivero, E.B; Torres Carbonell, P.; López Cabrera, M.I.; Buatois, L.A. 2008. Variaciones faciales y arquitecturas complejas en depósitos marinos someros de la Formación Leticia, Eoceno, Andes Fueguinos. In Reunión Argentina de Sedimentología, No. 12, Resúmenes: 128. Buenos Aires.

Olivero, E.B.; Malumián, N.; Martinioni, D.R. 2007. Mapa geológico de la Isla Grande de Tierra del Fuego e Isla de los Estados. Escala 1:500.000. Servicio Geológico Minero Argentino (SEGEMAR). Buenos Aires.

Ponce, J.J.; Olivero, E.B. 2008. Sediment transfer from shelf to deepwater. Revisiting the delivery mechanisms. Outcrop examples. American Association of Petroleum Geologists Hedberg Research Conference: 94 p. Ushuaia.

Ponce, J.J.; Olivero, E.B.; Martinioni, D.R. 2008. Upper Oligocene-Miocene clinoforms of the foreland Austral Basin of Tierra del Fuego, Argentina: Stratigraphy, depositional sequences and architecture of the foredeep deposits. Journal of South American Earth Sciences 26: 36-54.

Ramos, V.A. 2005. Seismic ridge subduction and topography: foreland deformation in the Patagonian Andes. Tectonophysics 399: 73-86.

Riba, O. 1976. Syntectonic unconformities of the Alto Cardener, Spanish Pyrenees: a genetic interpretation. Sedimentary Geology 15: 213-233.

Robbiano, J.A.; Arbe, H.A.; Gangui, A. 1996. Cuenca
Austral marina. Geología y Recursos Naturales de la Plataforma Continental Argentina (Ramos, V.A.; Turic, M.A.; editores). In Congreso Geológico Argentino, No. 12 y Congreso de Exploración de Hidrocarburos, No. 3, Relatorio: 323-341. Buenos Aires.

Scarpa, R.; Malumián, N. 2008. Foraminíferos del Oligoceno inferior de los Andes Fueguinos, Argentina: su significado tectónico-ambiental. Ameghiniana 45: 361-376.

Spezzaferri, S. 1994. Planktonic foraminiferal biostratigraphy and taxonomy of the Oligocene and lower Miocene in the oceanic record. An overview. Palaeontographia Italica 81: 1-187.

Suppe, J. 1985. Principles of structural geology. Prentice Hall: 537 p. New Jersey.

Suppe, J.; Chou, G.T.; Hook, S. 1992. Rates of folding and faulting determined from growth strata. In Thrust Tectonics (McClay, K.R.; editor). Chapman and Hall: 105-121. London.

Torres Carbonell, P.J.; Olivero, E.B.; Dimieri, L.V. 2008a. Structure and evolution of the Fuegian Andes foreland thrust-fold belt, Tierra del Fuego, Argentina: paleogeographic implications. Journal of South American Earth Sciences 25: 417-439.

Torres Carbonell, P.J.; Dimieri, L.V.; Olivero, E.B. 2008 b. Thrust-fold belt kinematics and orogenic growth in Tierra del Fuego, Argentina: implications of backthrusting for critical Coulomb wedge development. In International Meeting of Young Researchers in Structural Geology and Tectonics. Programme and Extended Abstracts: 101-105. Oviedo.

Twiss, R.J.; Moores, E.M. 2007. Structural Geology. Freeman and Co.: 736 p. New York.

Wilson, T.J. 1991. Transition from back-arc to foreland basin development in the southernmost Andes: Stratigraphic record from the Última Esperanza District, Chile. Geological Society of America Bulletin 103: 98-111.

Yrigoyen, M.R. 1989. Cuenca de Malvinas. In Cuencas sedimentarias argentinas (Chebli, G.A.; Spalletti, L.A.; editores). Universidad Nacional de Tucumán, Serie Correlación Geológica 6: 481-491. Tucumán. 